Wang. W, Martakos, G., Dulieu-Barton, J.M., Andreasen, J.H. and Thomsen, O.T., "Fracture Behaviour at trimaterial junctions of crack stoppers in sandwich structures" Composite Structures, 133, 2015, 818-833.

http://dx.doi.org/10.1016/j.compstruct.2015.07.060

\title{
Fracture Behaviour at Tri-material Junctions of Crack Stoppers in Sandwich Structures
}

\author{
W. Wang ${ }^{1}$, G. Martakos ${ }^{2}$, J.M. Dulieu-Barton ${ }^{1}$, J.H. Andreasen ${ }^{2}$, O.T. \\ Thomsen ${ }^{1,2}$ \\ ${ }^{1}$ Faculty of Engineering and the Environment, University of Southampton, Highfield, \\ Southampton, UK \\ ${ }^{2}$ Department of Mechanical and Manufacturing Engineering, Aalborg University, Aalborg, \\ Denmark
}

\begin{abstract}
:
Inspired by a previously published peel stopper design for foam cored composite sandwich structures, three novel markedly lighter peel stoppers were evaluated with respect to their ability to deflect and arrest propagating face debond cracks. Of the three novel peel stopper configurations, $\mathrm{C} 1, \mathrm{C} 2$ and $\mathrm{C} 3, \mathrm{C} 1$ was similar to the previous design, whereas $\mathrm{C} 2$ and $\mathrm{C} 3$ were modified with layers of glass fibre fabric extending from the peel stopper tip into the face sheet $(\mathrm{C} 2)$ or into the face sheet/core interface $(\mathrm{C} 3)$. The previous peel stopper was validated under mode II dominated conditions, but the novel designs were investigated under mode I dominated crack propagation conditions, which are of higher practical relevance. Both quasi-static and fatigue loading scenarios were investigated. The mechanisms controlling crack propagation at the internal peel stopper tip were studied using Thermoelastic Stress analysis (TSA) and Finite Element (FE) analysis. The TSA has revealed significant new information about the local stress fields in the vicinity of the tri-material junction (peel stopper tip) as well as the fracture process zone. Configuration $\mathrm{C} 1$ was unable to deflect debond cracks consistently, albeit it did so in most cases, whereas it was incapable of achieving crack arrest. C2 and $\mathrm{C} 3$ both performed better in that they consistently demonstrated the ability to deflect propagating cracks, whereas only $\mathrm{C} 2$ could arrest the cracks consistently as well. Detailed fracture mechanics analyses confirmed and explained the experimental observations.
\end{abstract}

Keywords: foam cored composite sandwich structures, peel stoppers, thermoelastic stress analysis, fracture modelling, damage tolerance

\section{INTRODUCTION}

A sandwich structure is a layered composite formed by attaching two thin but stiff face sheets to a thick but lightweight core material. Compared to monolithic structures or laminated composites, this structure is well known for its superior bending stiffness and strength to weight ratios [1]. A weakness of sandwich structures is the quality of the bonding between the face sheet and core. Debonds can initiate from manufacturing defects as well as in-service overload or impact. Propagation of the debonded area is often rapid due to the brittle behaviour of the face sheet/core interface bond, leading to face sheet detachment. The result is loss of strength and stiffness, which may lead to catastrophic failure. From a practical point of view it is desirable to suppress the debond propagation so that some of the loading 
Wang. W, Martakos, G., Dulieu-Barton, J.M., Andreasen, J.H. and Thomsen, O.T., "Fracture Behaviour at trimaterial junctions of crack stoppers in sandwich structures" Composite Structures, 133, 2015, 818-833.

http://dx.doi.org/10.1016/j.compstruct.2015.07.060

carrying capacity is retained. Therefore attention has been paid to the development of inserts in the core material to suppress interfacial debonding.

In several studies sub-structural elements (i.e. crack stoppers) made from carbon fibre reinforced plastic (CFRP) were proposed and applied to foam cored sandwich components to prevent the propagation of interfacial cracks. Hirose et al. [2, 3] introduced semi-circular shaped CFRP rods in the face sheet/core interface to increase the fracture toughness at the edge of the CFRP inserts. In their studies an increase of the critical load was observed as the crack tip approached the CFRP rods, which was attributed to the redistribution of the stresses between the crack tip and the CFRP rods. Rinker et al. [4] integrated a CFRP double-T joint element and a rectangular shaped CFRP element into the core. Sandwich structures with different embedded elements were investigated under fatigue loading and an increase of fatigue life was observed. Although the introduction of different CFRP inserts increases the interfacial fracture toughness, it was not possible to arrest the crack using these approaches. Moreover, the crack stoppers made from CFRP are much stiffer than the foam core material, which result in severe stress concentration that could initiate cracks.

A different concept was proposed by Jacobsen et al. [5-8], where the crack stopper was manufactured from a PolyUrethane (PU) material with stiffness properties similar to those of the foam core materials. A key element in the design was to confine and arrest the growth of the interfacial crack. The basic principle of the so-called 'peel stopper' is to deflect the crack away from the face sheet/core interface into the core, so that the crack path follows the boundary of the peel stopper. The functionality of the crack stopper was validated experimentally using three-point bend tests in which sandwich beams with aluminium or GFRP face sheets and Divinycell H60 PVC foam core were studied [5, 6]. It was shown that interfacial cracks that were initiated by core shear failure were successfully deflected and arrested by the peel stopper. The purpose of the present paper is to further explore the peel stopper concept. In particular two considerations emerge from the peel stopper design proposed in [5, 6]. Firstly, the loading conditions at the debond tip in [5] and [6] were mixed mode with significant contribution in mode II. However, many realistic loading situations are mode I dominated, hence there is a need to assess the ability of the peel stopper to deflect propagating interfacial cracks under this condition. Secondly, the bulky design of the peel stoppers accompanied by the high density of the PU material suggests that the use of the peel stoppers described in [5] and [6] will incur a serious weight penalty.

The work described in the present paper investigates the mechanisms controlling crack deflection in the neighbourhood of peel stoppers experiencing mode I dominated loading. The geometry of the peel stopper is modified to reduce its weight. Three new peel stopper configurations are proposed. Thermoelastic stress analysis (TSA) [9] and finite element (FE) analysis are used to derive the crack-tip stress field and to characterise the fracture behaviour in the neighbourhood of the peel stopper to assess the conditions to achieve successful crack deflection.

TSA is based on the thermoelastic effect where a small temperature change on the surface of a material is measured using infra-red (IR) imaging of the structure under cyclic load. For isentropic conditions, the temperature change $(\Delta T)$ divided by the absolute temperature $(T)$ is linearly proportional to the change in the sum of principal stresses [9]. Therefore, TSA is used to determine the stress state in the neighborhood of the peel stopper and to assess the stress evolution during crack growth. As high spatial resolution data can be obtained from TSA, the aim is to investigate the local effects (local stress concentrations) introduced by the 
Wang. W, Martakos, G., Dulieu-Barton, J.M., Andreasen, J.H. and Thomsen, O.T., "Fracture Behaviour at trimaterial junctions of crack stoppers in sandwich structures" Composite Structures, 133, 2015, 818-833.

http://dx.doi.org/10.1016/j.compstruct.2015.07.060

different peel stopper configurations and to understand the associated crack propagation mechanisms. A major challenge in obtaining the stress state from an interfacial crack is the large and discontinuous motion induced by the face sheet/core detachment. As the IR detector is stationary and the specimen is moving, each point on the specimen surface is detected by different elements of the detector array. This leads to erroneous measurement of the temperature change as IR detector cannot track the specimen motion. To address the complex motion expected for the mode I dominated loading of the sandwich specimen, a motion compensation technique has been developed [10]. Digital image correlation (DIC) [11] is used to track the specimen motion and incorporate the displacement field for motion correction of each pixel in the IR images.

In addition to TSA, a FE model was developed based on Suo's interfacial crack formulation [12] and implemented as a subroutine in ANSYS. The goal is to study the energy release rate and mode-mixity of a propagating crack at different locations around the peel stopper. Berggreen [13, 14] developed the so called Crack Surface Displacement Extrapolation (CSDE) method and implemented it in ANSYS as a subroutine. The method has been successfully used in combination with FE analysis to investigate interface cracks in sandwich structures. The CSDE method is utilized in this work since it enables calculations close to the crack tip while avoiding the oscillations in the solution that derive from the dissimilarity of material properties.

\section{Configurations of the peel stopper}

Three different configurations of peel stoppers are studied. In all cases the peel stopper geometry is as shown in Figure 1 (a) which is a modification of the original design by Jakobsen et al. [5]. Here the peel stopper is moulded into a ' $U$ ' shaped geometry so that the volume of material is significantly reduced, thus reducing the mass correspondingly. The PU material used for the peel stopper is reinforced by a layer of glass fibre fabric as shown in Figure 1 (b). Comparing to the original design, the glass fibre fabric is introduced to enhance the peel stopper fracture toughness and to prevent the crack from penetrating into the peel stopper.

The peel stopper is moulded in a ' $U$ ' shape using a mould made of Polypropylene. The polypropylene does not bond with the PU material making it a good choice for the mould tool as extra coatings are not required. The mould is shown in Figure 2 (a) which includes two parts: the lower and upper parts. The fabrication firstly applies the PU material in the lower part of the mould. The PU material is in liquid form and can take the shape of the mould. The UD fibres are then attached to the upper part with the main fibre direction following the arrows as shown in Figure 2 (a). Finally, the upper part of the mould together with the fibres are pressed into the lower part containing the PU adhesive. Figure 2 (b) shows the side view of the assembled mould where the gap between the upper and lower parts are filled with the PU and fibres. The mould is closed tightly using bolts and nuts to contain the material in the desired dimensions. When the mould is fully closed, the excess PU material is driven out by holes drilled in the mould body.

The three different configurations of peel stoppers are shown in Figure 3. In configuration 1 (C1), the PU material is directly bonded to the foam core. As the 'U' shaped peel stopper has the same wedge angle $\left(10^{\circ}\right)$ as that suggested in the original design, the configuration at the peel stopper tip of $\mathrm{C} 1$ remains the same as that of the original peel stopper. In configurations 2 (C2) and 3 (C3) modifications of small material features at the tri-material junction are 
Wang. W, Martakos, G., Dulieu-Barton, J.M., Andreasen, J.H. and Thomsen, O.T., "Fracture Behaviour at trimaterial junctions of crack stoppers in sandwich structures" Composite Structures, 133, 2015, 818-833.

http://dx.doi.org/10.1016/j.compstruct.2015.07.060

made. The aim is to change the local effects at the tri-material junction and thereby enabling crack deflection. In $\mathrm{C} 2$ the PU material is also directly bonded to the foam, but the glass fibre layer inside the PU material protrudes from the peel stopper tip. The fibre layer is infused together with the face sheet during the manufacturing process. In $\mathrm{C} 3$ an extra fibre layer is introduced at the PU/foam interface when the PU material is bonded to the foam. The part of fibre layer behind the peel stopper is attached to the face sheet as for $\mathrm{C} 2$.

In the following sections, the ability of the different peel stoppers to deflect the interfacial crack is examined under both static and fatigue loading. The experimental results obtained from the static tests are used to validate FE models of sandwich specimens containing the different peel stopper configurations. The mechanisms controlling the crack propagation in the vicinity of peel stoppers are then studied using both TSA and FE analysis.

\section{Test specimens}

The sandwich specimens studied in the present work consist of $25 \mathrm{~mm}$ cross-linked PVC foam cores (Divinycell H100) and $210 \mathrm{gm}^{-2}$ plain woven E-glass/epoxy composite face sheets. The core materials include two blocks of foam which have been machined to the required geometries using a CNC milling centre; the two blocks of foam are attached to the inner and outer side of the peel stopper as shown in Figure 3. The fibre layers introduced inside the peel stopper and placed at the peel stopper/core interface in C3 are made from the same E-glass fabric that was used for the face sheet. The material properties of the sandwich constituent materials are listed in Table $1[5,15]$.

Table 1. Mechanical properties of the constituent material in the sandwich structures $[5,15]$

\begin{tabular}{lcccc}
\hline Materials & $\begin{array}{c}\text { Young's modulus } \\
\left(E_{x}\right)\end{array}$ & $\begin{array}{c}\text { Young's modulus } \\
\left(E_{y}\right)\end{array}$ & $\begin{array}{c}\text { Shear modulus } \\
\left(G_{x y}\right)\end{array}$ & $\begin{array}{c}\text { Poisson's ratio } \\
\left(v_{\mathrm{xy}}\right)\end{array}$ \\
\hline Foam & $58 \mathrm{MPa}$ & $132 \mathrm{MPa}$ & $33 \mathrm{MPa}$ & 0.17 \\
Composite & $17 \mathrm{Gpa}^{*}$ & -- & $6.84 \mathrm{GPa}^{*}$ & $0.32^{*}$ \\
PU & $100 \mathrm{MPa}$ & -- & -- & -- \\
\hline
\end{tabular}

*obtained experimentally

The sandwich panel that incorporates the peel stopper was manufactured in a single shot resin infusion process using Prime $20 \mathrm{LV}$ epoxy resin by Gurit. Three panels each containing a peel stopper configuration (i.e. C1, C2 and C3) were manufactured. To create an initial debond behind the peel stopper tip, a thin Teflon film of $25 \mu \mathrm{m}$ thick was placed between the face sheet and the core across the width of the panel. Prior to the manufacturing, the peel stopper was adhesively boned to the foam using the Araldite 2000 epoxy adhesive as suggested in [5]. For C3, the extra fibre reinforcement layer was firstly placed on the foam (i.e. the block of foam that was attached to the inner side of the peel stopper) with the epoxy adhesive applied, and then the foam was bonded to the peel stopper.

For each configuration, four sandwich beam specimens of $210 \mathrm{~mm}$ length and $30 \mathrm{~mm}$ width were cut from the panels (one specimen was tested under static loading and the rest of the specimens were tested under fatigue loading). The specimens were loaded using the mixed mode bending test rig (MMB) as shown in Figure 4. The MMB test rig was used because the applied loading mode at the crack tip remains the same during the crack propagation [16]. 
Wang. W, Martakos, G., Dulieu-Barton, J.M., Andreasen, J.H. and Thomsen, O.T., "Fracture Behaviour at trimaterial junctions of crack stoppers in sandwich structures" Composite Structures, 133, 2015, 818-833.

http://dx.doi.org/10.1016/j.compstruct.2015.07.060

Table 2 summarises the dimensions of each sandwich specimen and its loading conditions. A long level arm distance, $c$, was applied in the tests to provide a mode I dominated loading. The mode-mixity, $\psi$, shown in the table (predicted by the FE model described in section 4) confirms that a mode I dominated loading was applied to different specimens and configurations. As shown in Figure 4, the distance between the initial crack tip and the peel stopper tip is relatively long $(15 \mathrm{~mm})$ to allow the crack to propagate before reaching the trimaterial junction. This is important, as a well-defined stable crack growth must be achieved behind the peel stopper tip.

Table 2. Dimensions and the loading conditions of each sandwich specimen

\begin{tabular}{lccccc}
\hline Specimen & $\begin{array}{c}\text { Peel stopper } \\
\text { configuration }\end{array}$ & $\begin{array}{c}\text { Initial crack } \\
\text { length } \\
\left(a_{0}, \mathrm{~mm}\right)\end{array}$ & $\begin{array}{c}\text { Face sheet } \\
\text { thickness } \\
\left(t_{f}, \mathrm{~mm}\right)\end{array}$ & $\begin{array}{c}\text { Lever arm } \\
\text { distance } \\
(c, \mathrm{~mm})\end{array}$ & $\begin{array}{c}\text { Mode- } \\
\text { mixity } \\
\left(\psi,{ }^{\circ}\right)\end{array}$ \\
\hline C1_s1 (static) & & 14 & 1.6 & 60 & -12.6 \\
C1_f1 (fatigue) & $\mathrm{C} 1$ & 17 & 1.6 & 75 & -10.2 \\
C1_f2 (fatigue) & & 18 & 1.6 & 75 & -10.2 \\
C1_f3 (fatigue) & & 18 & 1.6 & 75 & -10.2 \\
\hline C2_s1 (static) & & 13.5 & 1.7 & 60 & -12.9 \\
C2_f1 (fatigue) & & 17 & 1.7 & 75 & -10.4 \\
C2_f2 (fatigue) & $\mathrm{C} 2$ & 19 & 1.7 & 75 & -10.5 \\
C2_f3 (fatigue) & & 19.5 & 1.7 & 75 & -10.5 \\
\hline C3_s1 (static) & & 14 & 1.7 & 60 & -12.5 \\
C3_f1 (fatigue) & & 15.5 & 1.7 & 75 & -9.7 \\
C3_f2 (fatigue) & $\mathrm{C} 3$ & 19 & 1.7 & 75 & -9.9 \\
C3_f3 (fatigue) & & 20 & 1.7 & 75 & -9.9 \\
\hline
\end{tabular}

\section{FE modelling}

\subsection{Fracture at bi-material interface}

To account for anisotropy in the neighbourhood of the bi-material interface Suo's formulation was used [12]. Furthermore the Crack Opening Displacement (COD) approach is adapted for bi-material problems in a Finite Element Analysis (FEA) framework so the required displacements at the crack tip are calculated from the predicted nodal displacements. The formulation includes material anisotropy parameters $H_{11}$ and $H_{22}$, Dundur's parameters for dissimilar crack interface materials and the oscillation parameter $\varepsilon[12,17-19]$. The parameter $\varepsilon$ accounts for the oscillations of mode-mixity and energy release rate in the FEA close to the crack tip.

The anisotropy parameters, $H_{11}$ and $H_{22}$, are implemented in the COD formulation as follows [12]: 
Wang. W, Martakos, G., Dulieu-Barton, J.M., Andreasen, J.H. and Thomsen, O.T., "Fracture Behaviour at trimaterial junctions of crack stoppers in sandwich structures" Composite Structures, 133, 2015, 818-833.

http://dx.doi.org/10.1016/j.compstruct.2015.07.060

$\sqrt{\frac{H_{11}}{H_{22}}} \delta_{y}+i \delta_{x}=\frac{2 H_{11}\left(K_{1}+i K_{2}\right)|x|^{\frac{1}{2}+i \varepsilon}}{\sqrt{2 \pi}(1+2 i \varepsilon) \cosh \pi \varepsilon}$

$\sqrt{\frac{H_{11}}{H_{22}}} \sigma_{y y}+i \sigma_{x y}=\frac{K x^{i \varepsilon}}{\sqrt{2 \pi x}}$

where $x$ represents the distance away from the crack tip (see Figure 5 (a)) and $K$ is the complex stress intensity factor $K_{1}+i K_{2}$. The opening and shear displacements are represented by $\delta_{y}$ and $\delta_{x}$ respectively in the local coordinate system as shown in Figure 5 (a).

Also it can be shown that [12]:

$$
\begin{aligned}
& K x^{i \varepsilon}=\left[K_{1} \cos (\varepsilon \ln x)-K_{2} \sin (\varepsilon \ln x)\right]+i\left[K_{2} \cos (\varepsilon \ln x)+K_{1} \sin (\varepsilon \ln x)\right] \\
& \psi=\arctan \left[\frac{\mathfrak{I}\left(K h^{i \varepsilon}\right)}{\mathfrak{R}\left(K h^{i \varepsilon}\right)}\right] \\
& G=\frac{H_{11}|K|^{2}}{4 \cosh ^{2}(\pi \varepsilon)}
\end{aligned}
$$

where $G$ is the energy release rate and $\psi$ is the mode-mixity of the crack.

By substituting equations (1) and (2) into equations (4) and (5) yields:

$$
\begin{aligned}
& \psi=\arctan \left(\sqrt{\frac{H_{11}}{H_{22}}} \frac{\delta_{x}}{\delta_{y}}\right) \\
& G=\frac{\pi\left(1+4 \varepsilon^{2}\right)}{8 H_{11}|x|}\left(\frac{H_{11}}{H_{22}} \delta_{y}{ }^{2}+\delta_{x}{ }^{2}\right)
\end{aligned}
$$

In equations (6) and (7) the oscillation term, $x^{i \varepsilon}$, has been eliminated, however for very small elements the crack tip singularity may still introduce numerical instability. The CSDE method $[13,14]$ is utilized as shown in Figure $5(\mathrm{~b})$ to suppress any numerical errors near to the crack tip. The CSDE method calculates the energy release rate and mode-mixity over a region of the crack surface and identifies the sub-region where the oscillation is not affecting the results. Then by using outer and inner limit values of the energy release rate and the mode-mixity (see Figure 5 (b)) linear extrapolation is used to calculate the values at the crack tip.

\subsection{FE modelling}

FE models of the test specimens were constructed using the commercial FE package ANSYS 15.0 [20]. The two scenarios of crack deflection and crack propagating along the horizontal interface (i.e. no crack deflection) at the tri-material junction were modeled for each peel stopper configuration. 8-node 2D plane stress elements (PLANE 183) with an average element size of $0.5 \mathrm{~mm}$ were used. Near the crack tip, the number of elements ranged from 36 to 144 with element sizes of 5 to $10 \mu \mathrm{m}$. Figure 6 shows the FE meshes corresponding to the 
Wang. W, Martakos, G., Dulieu-Barton, J.M., Andreasen, J.H. and Thomsen, O.T., "Fracture Behaviour at trimaterial junctions of crack stoppers in sandwich structures" Composite Structures, 133, 2015, 818-833.

http://dx.doi.org/10.1016/j.compstruct.2015.07.060

three peel stopper configurations and the geometry of the sandwich beam model. The detailed models of different crack path scenarios around the tri-material junction for each configuration are shown in the images a-f in Figure 6. In the models of $\mathrm{C} 2$ and $\mathrm{C} 3$, an extra layer of elements of $0.1 \mathrm{~mm}$ thickness (shown in orange) was used to model the protruding fibre layer and the inter-fibre layer. In $\mathrm{C} 2$ the extra fibre layer was attached to the tri-material tip to model the fibres protruding from the peel stopper.

\section{Experimental setup}

Sandwich specimens mounted in the MMB rig were tested in an Instron ElectroPuls machine (E1000) with a $1 \mathrm{kN}$ actuator and load cell capacity. The actuator of the test machine was connected to the loading yoke (see Figure 4), which applied the downward force to the MMB test fixture.

The static tests were conducted with a displacement rate of $1 \mathrm{~mm} / \mathrm{min}$. To validate the FE models described in section 4, the load-displacement data output from the test machine were recorded and compared to the FE results. The crack lengths input into the FE models were obtained from the images recorded by a camera. The images were recorded simultaneously with the load and displacement data, and were calibrated using a pre-applied scale on the specimen surface.

The fatigue tests were performed using displacement control as the displacement controlled tests generally offer more stable test conditions and promote stable crack growth. A displacement ratio $R\left(\delta_{\min } / \delta_{\max }\right)=0.2$, and a loading frequency of $3 \mathrm{~Hz}$ were used. In the tests TSA was performed to determine the local effects at the tri-material junction of the face sheet, core and the peel stopper. The experimental setup for the TSA is shown in Figure 7. The IR camera captured the thermal images for TSA with a frame rate of $383 \mathrm{~Hz}$. To perform the motion compensation, images for DIC were captured by a white light camera placed behind the IR camera. To correlate the displacement field and the thermal image, both cameras were aligned perpendicular to the specimen surface [10]. The IR camera was placed on a tripod which allows the camera to be moved up and down vertically. Thus, when the white light camera captures the images, the position of the IR camera was adjusted, so the white light camera could observe the specimen. A detailed description of the fatigue test procedure is provided in section 6 .

The IR system used in this work is the FLIR SC5500 series. The system includes a photon detector, sensitive to radiation with wavelengths from 3 to $5 \mu \mathrm{m}$. The detector is a $320 \times 256$ pixel indium/antimonide (InSb) sensor array. In standard operation the detector has a sensitivity of $4.2 \mathrm{mK}$ at $25{ }^{\circ} \mathrm{C}$ and a maximum frame rate of $383 \mathrm{~Hz}$. The system enables the use of a magnifying lens (L0510×0.5) which provided a region of interest of $17.9 \times 14.3 \mathrm{~mm}^{2}$, with a spatial resolution of $0.06 \mathrm{~mm} /$ pixel. The white light camera used for motion compensation was a LA Vision VC-Imager E-lite digital camera with 5 mega-pixel sensor array. To achieve a similar field of view to that of the thermal data, a $105 \mathrm{~mm}$ lens (SIGMA) was used. The lens was set with a scale factor of $0.01 \mathrm{~mm} /$ pixel to provide a region of interest of $24 \times 22 \mathrm{~mm}^{2}$. Displacements of the specimen were computed from the recorded white light images using the commercial DIC software (DaVis 8) produced by LAVison.

The thermal and white light images collected in the neighbourhood of the tri-material junction are shown in Figure 8 (a) and (b) respectively. In both images the position of the peel stopper is marked by the red dashed line. A small piece of foil was attached to the face 
Wang. W, Martakos, G., Dulieu-Barton, J.M., Andreasen, J.H. and Thomsen, O.T., "Fracture Behaviour at trimaterial junctions of crack stoppers in sandwich structures" Composite Structures, 133, 2015, 818-833.

http://dx.doi.org/10.1016/j.compstruct.2015.07.060

sheet to help identify the position of the peel stopper tip. The position masks placed on the specimen surface was used to align the thermal and white light images so that the displacement vector corresponding to each IR pixel can be located [10]. The white rectangular area bounded by the position marks is the region of interest (i.e. the area where the motion compensation was applied). The grid shown in Figure 8 (b) shows the interrogation cells used for the DIC.

\section{Fatigue test procedure}

A disadvantage of the displacement controlled fatigue test is that the energy release rate decreases with crack growth. This means that more loading cycles are required to achieve the desired crack length. The specimens were tested until the crack length was about $25 \mathrm{~mm}$, i.e. $10 \mathrm{~mm}$ after the peel stopper tip. During the crack propagation the energy release rate will decrease significantly, and the crack may stop growing before it has reached the peel stopper. Therefore during the tests it is necessary to change the displacement amplitude to control the $\Delta G$ at the prescribed value (see Figure 9 (a)). The ' $\Delta G$ control' is described in Figure 9 (b). Firstly the FE model described in section 4 is used to predict the maximum displacement $\left(\delta_{\max }\right)$ shown by the black line in Figure 9 (b). A $\Delta G$ of $450 \mathrm{~J} / \mathrm{m}^{2}$ was selected which is smaller than the interfacial fracture toughness of the sandwich specimens studied in this work [21]. For the small displacement ratio of $R=0.2$ the difference between $\Delta G$ and $G_{\max }$ is insignificant [22]. Thus, $\delta_{\max }$ can be obtained directly using the value of $450 \mathrm{~J} / \mathrm{m}^{2}$, so $\delta_{\max }$ was calculated in increments of $1 \mathrm{~mm}$ (note the $0 \mathrm{~mm}$ crack increment as shown in Figure 9 (b) corresponds to the initial crack length). The displacement amplitude $\left(\delta_{\text {amp }}\right)$ and the mean displacement $\left(\delta_{\text {mean }}\right)$ were calculated according to the $\delta_{\max }$ and displacement ratio $(R)$ as follows:

$$
\begin{aligned}
& \delta_{\text {amp }}=\frac{\delta_{\max }-R \delta_{\text {max }}}{2} \\
& \delta_{\text {mean }}=R \delta_{\text {max }}+\delta_{\text {amp }}
\end{aligned}
$$

The fatigue test was initially setup by using the $\delta_{\text {amp }}$ and $\delta_{\text {mean }}$ calculated at $0 \mathrm{~mm}$ crack increment. This allowed the fatigue test to be started with $\Delta G$ of $450 \mathrm{~J} / \mathrm{m}^{2}$. The $\delta_{\text {mean }}$ and the $\delta_{\text {amp }}$ were then adjusted for each $2 \mathrm{~mm}$ crack increment as indicated by the red line shown in Figure 9 (b). By doing this, the $\Delta G$ value was maintained close to $450 \mathrm{~J} / \mathrm{m}^{2}$ throughout the test.

The fatigue test procedure is described by the flowchart shown in Figure 10. The test was started using the $\delta_{\text {amp }}$ and $\delta_{\text {mean }}$ derived at $0 \mathrm{~mm}$. When the crack tip has moved by $2 \mathrm{~mm}$, the test was paused. The $\delta_{\text {amp }}$ and $\delta_{\text {mean }}$ values were adjusted and the fatigue test was restarted using the new $\delta_{\text {amp }}$ and $\delta_{\text {mean }}$ values. This process was continued until the crack propagated into the neighbourhood of the tri-material junction (i.e. when the distance between the crack tip and the peel stopper tip was smaller than $6 \mathrm{~mm}$ ). During the process, the crack tip location was determined from the live thermal images where the pixel resolution was calibrated beforehand using a pre-applied scale on the specimen surface. Once the crack tip reached the region of interest, the fatigue test was paused after a set of 1200 thermal images was recorded for the TSA, and the position of the IR camera adjusted. The images for DIC were then captured as the specimen was loaded quasi statically over a range equivalent to the dynamic loading range. The fatigue test was restarted using the new $\delta_{\text {amp }}$ and $\delta_{\text {mean }}$ values and the IR camera returned to its original position to observe the region of interest. For each $2 \mathrm{~mm}$ crack 
Wang. W, Martakos, G., Dulieu-Barton, J.M., Andreasen, J.H. and Thomsen, O.T., "Fracture Behaviour at trimaterial junctions of crack stoppers in sandwich structures" Composite Structures, 133, 2015, 818-833.

http://dx.doi.org/10.1016/j.compstruct.2015.07.060

increment, the sequence of thermal and white light images capture was repeated until the crack had propagated $10 \mathrm{~mm}$ beyond the tri-material junction.

\section{Fracture testing results}

Table 3 summarises the crack paths of the different specimens observed in the static tests. It was observed that the crack was successfully deflected at the tri-material junction in specimens $\mathrm{C} 2$ and $\mathrm{C} 3$. However, $\mathrm{C} 1$ which essentially was of the same design configuration at the tri-material junction of the original peel stopper cannot deflect the crack efficiently. After the crack passed the peel stopper tip, a debond was observed at the face sheet/peel stopper interface in specimens $\mathrm{C} 1$ and $\mathrm{C} 3$. This could be caused by defects introduced during the manufacturing process.

Table 3 Crack paths observed from different specimens in the static tests

\begin{tabular}{cccc}
\hline Specimen & $\begin{array}{c}\text { Peel stopper } \\
\text { configuration }\end{array}$ & $\begin{array}{c}\text { Crack paths at the tri-material } \\
\text { junction }\end{array}$ & $\begin{array}{c}\text { Post crack deflection } \\
\text { behaviour }\end{array}$ \\
\hline C1_s1 & C1 & $\begin{array}{c}\text { Deflection occurred at one } \\
\text { side of the specimen } \\
\text { Deflection occurred at both } \\
\text { sides of the specimen } \\
\text { C2_s2 }\end{array}$ & $\begin{array}{c}\text { Debond occurred at the face } \\
\text { sheet/peel stopper interface }\end{array}$ \\
C3_s3 & C3 & $\begin{array}{c}\text { Deflection occurred at both } \\
\text { sides of the specimen }\end{array}$ & $\begin{array}{c}\text { Nebond occurred at the face } \\
\text { sheet/peel stopper interface }\end{array}$ \\
\hline
\end{tabular}

The crack paths of the different specimens observed in the fatigue tests are summarised in Table 4. The crack paths at the tri-material junction of different configurations are similar as those observed in the static tests. In specimens $\mathrm{C} 1$ the crack propagated in the foam just below the interface as it approached the tri-material junction. There are two specimens (C1_f2 and $\mathrm{C} 1$ f 3 ) where the crack did not deflect at the tri-material junction. Figure 11 shows the crack paths captured at the tri-material junction from specimens $\mathrm{C} 1$. In all cases the crack kinked back towards to the face sheet at the tri-material junction resulting in the crack propagating at the face sheet/peel stopper interface in specimens $\mathrm{C} 1 \_\mathrm{f} 2$ and $\mathrm{C} 1 \_\mathrm{f} 3$. In specimens $\mathrm{C} 2$ the crack firstly propagated at the face sheet/core interface and then grew in the foam just below the interface. In specimens C3 the crack propagated with different paths as it approached the tri-material junction. The crack propagated along the face sheet /core interface in specimens $\mathrm{C} 3 \_\mathrm{f} 1$ and $\mathrm{C} 3$ f 2 . In specimen $\mathrm{C} 3$ f 3 the crack firstly propagated along the interface and then grew in the foam. The crack paths at the tri-material junction obtained from specimens C3_f1 (i.e. crack tip in the face sheet) and C3 f3 (i.e. crack tip in the foam core) show that the crack deflected regardless of where the crack tip was located. Additionally, in all cases there was no debonding at the face sheet/peel stopper interface, unlike the static test results.

Table 4 Crack paths observed from different specimens in the fatigue tests

\begin{tabular}{cccc}
\hline Specimen & $\begin{array}{c}\text { Peel Stopper } \\
\text { configuration }\end{array}$ & $\begin{array}{c}\text { Crack paths before the } \\
\text { tri-material junction }\end{array}$ & $\begin{array}{c}\text { Crack paths at the tri- } \\
\text { material junction }\end{array}$ \\
\hline C1_fl & & Foam & Deflected
\end{tabular}


Wang. W, Martakos, G., Dulieu-Barton, J.M., Andreasen, J.H. and Thomsen, O.T., "Fracture Behaviour at trimaterial junctions of crack stoppers in sandwich structures" Composite Structures, 133, 2015, 818-833.

http://dx.doi.org/10.1016/j.compstruct.2015.07.060

\begin{tabular}{cccc} 
C1_f2 & C1 & Foam & Not deflected \\
C1_f3 & & Foam & Not deflected \\
\hline C2_f1 & & Interface, foam & Deflected \\
C2_f2 & C2 & Interface, foam & Deflected \\
C2_f3 & & Interface, foam & Deflected \\
\hline C3_f1 & & Interface & Deflected \\
C3_f2 & C3 & Interface & Deflected \\
C3_f3 & & Interface, foam & Deflected \\
\hline
\end{tabular}

To validate the FE models, the loads and the corresponding crack lengths (determined from white light images) recorded in the static tests were input into the models for deriving the actuator displacement $\left(\delta_{\mathrm{MMB}}\right)$ based on the relationship given by [16]:

$\delta_{\mathrm{MMB}}=\delta_{1}+\frac{c}{L}\left(\delta_{1}+\delta_{2}\right)$

where $\delta_{1}$ is the displacement of the central 'roller' line of the sandwich beam specimen (see Figure 4 ) and $\delta_{2}$ is the crack tip opening displacement. $\delta_{1}$ and $\delta_{2}$ were obtained from the nodal displacements derived from the FE models.

Figure 12 plots the load-displacement data obtained from the experiments and the FEA for the different peel stopper configurations. The red dashed line shown in the figures indicates the value of the actuator displacement when the crack tip passed the peel stopper tip, i.e. the load-displacement curve shown on the right hand side of the red line was obtained after the crack tip passed the peel stopper tip. For specimen C1, two crack paths were observed across the specimen width when the crack passed the peel stopper tip. Thus, the load-displacement data on the right hand side of the red line are not available from the FE model. For all the different peel stopper configurations, the FE results show a good agreement with the results obtained from the experiments. This indicates that the FE model can predict the specimen behaviour during the crack propagation.

\section{TSA results}

TSA results collected in the neighbour of the peel stopper tip are presented in the form of the non-dimensional stress metric, $\Delta T / T$, which is linear proportional to the change in the sum of principle stresses (i.e. $\Delta \sigma_{\mathrm{x}}+\Delta \sigma_{\mathrm{y}}$ ). The thermoelastic constant, $K_{T}$, is a material parameter that defines this proportionality (i.e. $\left.\Delta T / T=K_{T}\left(\Delta \sigma_{\mathrm{x}}+\Delta \sigma_{\mathrm{y}}\right)\right)$. An example showing the difference in the $\Delta T / T$ data before and after applying the motion compensation is shown in Figure 13 as the crack propagated in the foam and reached the tri-material junction. After applying motion compensation, a localised increase in $\Delta T / T$ at the tri-material junction, i.e. in the face sheet and at the crack tip, can clearly be observed in Figure 13 (b).

Figure 14 shows the $\Delta T / T$ values obtained in the vicinity of the tri-material junction from specimens $\mathrm{C}$. In Figure 14 Images 1, Images 2 and Images 3 were obtained when crack approached, reached and passed the tri-material junction respectively. As the crack approached the tri-material junction (see Images 1), the through-thickness stress gradient changes from compression to tension, as does the stress concentration in the foam just below the interface at the crack tip. As the thermoelastic constant of the foam is about 20 times 
Wang. W, Martakos, G., Dulieu-Barton, J.M., Andreasen, J.H. and Thomsen, O.T., "Fracture Behaviour at trimaterial junctions of crack stoppers in sandwich structures" Composite Structures, 133, 2015, 818-833.

http://dx.doi.org/10.1016/j.compstruct.2015.07.060

higher than that of the E-glass/epoxy composites [23], this indicates that the stress produced in the face sheet is much higher than that at the crack tip. When the crack reached the trimaterial junction (Images 2), large $\Delta T / T$ values were obtained from the face sheet on the right hand side ahead of the peel stopper. The $\Delta T / T$ values in the face sheet ahead of the peel stopper tip are of comparable magnitude to those in the foam below the peel stopper tip (i.e. the crack tip). After the crack passed the tri-material junction, two crack paths were observed in specimens $\mathrm{C} 1$ as described in section 6.1. Although the crack was deflected in specimen C1_f1, an increase in $\Delta T / T$ in the face sheet close to the face sheet/peel stopper interface is seen in Image 3. This may be due to weak bonding between the face sheet and the peel stopper. In specimens C1_f2 and C1_f3, the crack was not deflected; hence large $\Delta T / T$ values are generated in the face sheets.

Figure 15 shows the $\Delta T / T$ data obtained from specimens $\mathrm{C} 2$. Here in all specimens the crack propagated in the foam just below the interface and was deflected at the tri-material junction. The $\Delta T / T$ values obtained as the crack approached the tri-material junction (see Images 1) show similar results to specimens $\mathrm{C} 1$. When the crack reached the tri-material junction (see Images 2), the $\Delta T / T$ value in the face sheet ahead of the peel stopper tip was much smaller than observed in $\mathrm{C} 1$. Moreover, an increase in $\Delta T / T$ occurs at the peel stopper/core interface compared to that observed for $\mathrm{C} 1$. After the crack passed the tri-material junction, large $\Delta T / T$ values were produced around the peel stopper/core interface. The $\Delta T / T$ values in the face sheet ahead of the peel stopper tip were much smaller than those observed in $\mathrm{C} 1$.

The $\Delta T / T$ values obtained from specimens $\mathrm{C} 3$ are shown in Figure 16 . When the crack approached the tri-material junction (see Images 1), the $\Delta T / T$ values were similar to those obtained from specimens $\mathrm{C} 1$ and $\mathrm{C} 2$. When the crack reached the tri-material junction (see Images 2), the $\Delta T / T$ fields obtained from different crack tip locations (i.e. in the face sheet/core interface or in the foam core) were comparable to those observed from $\mathrm{C} 2$, i.e. large $\Delta T / T$ values were only produced on the left hand side of the peel stopper tip accompanied by an increase in $\Delta T / T$ at the peel stopper/core interface. After the crack was deflected, an increase in the $\Delta T / T$ values was observed in a small area ahead of the peel stopper tip; this was not the case for $\mathrm{C} 1$ and $\mathrm{C} 2$.

The local effects introduced by different peel stopper configurations have been identified using the TSA data collected from the neighbourhood of the tri-material junctions. It was shown that the local effects are strongly dependent on the peel stopper configurations, especially when the crack reached and passed the tri-material junction.

When crack reached the tri-material junction, it is shown that the increase in $\Delta T / T$ in the face sheet ahead of the peel stopper tip is more significant in specimen $\mathrm{C} 1$ than that in specimens $\mathrm{C} 2$ and $\mathrm{C} 3$. Furthermore, an increase in $\Delta T / T$ at the peel stopper/core interface is observed in $\mathrm{C} 2$ and $\mathrm{C} 3$. The TSA results for $\mathrm{C} 1$ indicate that large longitudinal stresses $\left(\sigma_{\mathrm{x}}\right)$ exist in the face sheet ahead of the peel stopper tip. It is important to note that the stresses in the face sheet are predominantly in plane, conversely in the foam the thermoelastic response is dominated by the transverse normal stresses. So the $\sigma_{\mathrm{x}}$ values in the core area below the face sheet/peel stopper interface in $\mathrm{C} 1$ are much smaller compared to those in the face sheet. In $\mathrm{C} 2$ and $\mathrm{C} 3$, this is not the case as an increase in $\Delta T / T$ is identified at the peel stopper/core interface (the increase in $\Delta T / T$ in the face sheet ahead of the peel stopper tip is insignificant), indicating that $\sigma_{\mathrm{x}}$ has influence in both the face sheet and the peel stopper. If the bending moment that produces $\sigma_{\mathrm{x}}$ only acts on the face sheet, it induces large peeling stresses between the face sheet and the peel stopper. Furthermore, compressive transverse normal stresses are 
Wang. W, Martakos, G., Dulieu-Barton, J.M., Andreasen, J.H. and Thomsen, O.T., "Fracture Behaviour at trimaterial junctions of crack stoppers in sandwich structures" Composite Structures, 133, 2015, 818-833.

http://dx.doi.org/10.1016/j.compstruct.2015.07.060

induced across the face sheet/peel stopper interface ahead of the crack tip as shown in Figure 17 (a). This explains the crack path in specimens $\mathrm{C} 1$ where the crack kinked back towards to the face sheet at the tri-material junction. On the other hand, if the bending moment acts on both the face sheet and the peel stopper as in $\mathrm{C} 2$ and $\mathrm{C} 3$, peeling stresses are induced at the peel stopper/core interface as illustrated in Figure 17 (b). Hence, facilitating the crack deflection at the tri-material junction.

The specific peel stopper configuration also influences the stress state after the crack deflection has occurred. In specimens $C 1$ large $\Delta T / T$ values can be observed near the face sheet/peel stopper interface as shown by Images 3 of Figure 14. In C3 an increase of the $\Delta T / T$ values can be also observed around the face sheet/peel stopper interface (see Images 3 of Figure 16), but is most noticeable in the area close to the peel stopper tip. Compared to specimens $\mathrm{C} 1$ and $\mathrm{C} 3$, the increase in $\Delta T / T$ values at the face sheet/peel stopper interface is much smaller for the specimens C2 (see Images 3 of Figure 15). The reason for the relatively large $\Delta T / T$ values observed ahead of the peel stopper tip for the $\mathrm{C} 3$ specimens is not entirely clear, but it may be caused by defects introduced during the manufacturing, for example that the inter-fibre layer may not be bonded perfectly to the peel stopper tip and the face sheet at the tri-material junction, and also voids and a resin rich area may be introduced at the trimaterial junction as sketched in Figure 18. This may be caused by two different mechanisms: 1) the applied vacuum in combination with the atmospheric pressure, which together drives the infusion process, may not be sufficient to assure that air bubbles are not entrapped and that full wetting of the glass fabric is achieved at the tri-material junction; 2) the geometry of the peel stopper tip is imperfect (i.e. not a perfect wedge). This large $\Delta T / T$ values ahead of the peel stopper tip observed in $\mathrm{C} 1$ and $\mathrm{C} 3$ specimens indicate a weak bonding at the face sheet/peel stopper interface which can result in the debond damage. Thus, the TSA results provide a clear indication of the reasons why significant debond damage was observed for specimens $\mathrm{C} 1$ and $\mathrm{C} 3$ during the static tests.

\section{FE analysis}

The case of crack deflection for the crack passing the tri-material junction was analysed. The predicted energy release rate and the mode-mixity values were compared to the experimentally observed crack paths. The paths consist of the "straight path" for the crack penetrating the peel stopper, and the "deflected path" for the crack deflecting at the peel stopper. The ability to achieve crack deflection wrt. the peel stopper angle $\theta$ was also investigated (see Figure 19). The peel stopper angle, $\theta$ was varied from 5 to 30 degrees with steps of 5 degrees, and with a kinked crack length of $0.5 \mathrm{~mm}$ away from the corner as shown in Figure 19. The $10^{\circ}$ angle represents the tested configuration.

In Figure 20, the predicted energy release rates (left) and mode-mixities (right) for the two different crack paths are plotted as functions of the peel stopper angle $\theta$ for configurations $\mathrm{C}$, $\mathrm{C} 2$ and $\mathrm{C} 3$. From Figure 20 it is observed that the energy release rate for a crack propagating straight through the tri-material junction for $\mathrm{C} 1$ is not affected significantly by changing the peel stopper angle. For C2 and C3 though, the peel stopper angle influences the energy release rate significantly, as the protruding fibers (C2) and the inter fiber layer (C3) follow the changing value of $\theta$. Thus, the value of the angle $\theta$ has an effect on the local stiffness around the crack tip, and this directly affects the energy release rate. For the deflected crack paths, it is seen that the change in energy release rate is very small for $\mathrm{C} 1$ and $\mathrm{C} 2$, but for $\mathrm{C} 3$ a large and nearly linear drop of the predicted energy release rate is observed with increasing angle $\theta$. 
Wang. W, Martakos, G., Dulieu-Barton, J.M., Andreasen, J.H. and Thomsen, O.T., "Fracture Behaviour at trimaterial junctions of crack stoppers in sandwich structures" Composite Structures, 133, 2015, 818-833.

http://dx.doi.org/10.1016/j.compstruct.2015.07.060

Figure 20 also shows that for all 3 peel stopper configurations only small changes of the mode mixities are predicted with increasing $\theta$-value for the case of a crack propagating straight through the tri-material junction. For the deflected crack paths it is observed for all 3 configurations that the mode-mixity decreases with increasing $\theta$. Further, for $\mathrm{C} 1$ and $\mathrm{C} 2$ the mode-mixity becomes negative for increasing $\theta$, whereas it remains positive for every $\theta$-angle for $\mathrm{C} 3$. Even though the mode-mixity changes for the deflected crack path with increasing $\theta$, the shear component only increases significantly for very high deflection angles. For small deflection angles the mode-mixity is such that the crack experiences mode I dominant conditions for both the straight and the deflected crack paths.

The numerical results are used together with a criterion for crack kinking proposed in [17] to substantiate and explain the experimental observations. According to this criterion the condition for a crack to kink out of an interface can be expressed by the inequality [17]:

$$
\frac{G_{\text {straight }}}{\Gamma(\psi)_{\text {straight }}}<\frac{G_{\text {deflected }}}{\Gamma(\psi)_{\text {deflected }}}
$$

where $G_{\text {straight }}$ is the calculated energy release rate at the face sheet/core interface (i.e. for a crack growing along the straight path), and $G_{\text {deflected }}$ is the energy release rate corresponding to a given deflection angle $\theta$ which is identical to the peel stopper angle. $\Gamma(\psi)$ represents the interface fracture toughness values corresponding to the straight and deflected crack paths at a given mode-mixity angle $\psi$. Since the interface fracture toughness values are unknown, the considerations presented are qualitative rather than quantitative, and based on the calculated energy release rate and mode-mixity values alone.

Figure 20 shows that for each peel stopper configuration and for every peel stopper angle the energy release rate of the deflected crack path is lower than the energy release rate for the straight crack path. Thus, for all configurations and peel stopper angles the following inequality hold true:

$$
G_{\text {straight }}>G_{\text {deflected }}
$$

Further, the criterion for crack deflection (kinking) given by the inequality (9), can be rearranged as follows:

$$
\frac{G_{\text {deflected }}}{G_{\text {straight }}}>\frac{\Gamma(\psi)_{\text {deflected }}}{\Gamma(\psi)_{\text {straight }}}
$$

The two inequalities (11) and (12) show that crack kinking is highly dependent on the ratio between the two interface fracture toughnesses $\Gamma(\psi)_{\text {deflected }}$ and $\Gamma(\psi)_{\text {straight }}$. It can further be deducted that a propagating crack will have a tendency to stay close to the straight interface where the energy release rate is higher, rather than to follow the deflected crack path.

From Figure 20 it can also be observed that the mode-mixity remains highly mode I dominant which means that the interface fracture toughness of each path is close to its mode I fracture toughness $[17,18]$.

Based on the numerical results presented in Figure 20 the ratio $\frac{G_{\text {deflected }}}{G_{\text {straight }}}$ can be expressed for different crack deflection angles as shown in Figure 21. Then it follows from equation (12), that for each peel stopper configuration the crack will kink when the fracture toughness 
Wang. W, Martakos, G., Dulieu-Barton, J.M., Andreasen, J.H. and Thomsen, O.T., "Fracture Behaviour at trimaterial junctions of crack stoppers in sandwich structures" Composite Structures, 133, 2015, 818-833.

http://dx.doi.org/10.1016/j.compstruct.2015.07.060

ratio $\frac{\Gamma(\psi)_{\text {deflected }}}{\Gamma(\psi)_{\text {straight }}}$ is smaller than the energy release rate ratio $\frac{G_{\text {deflected }}}{G_{\text {straight }}}$ for a given peel stopper angle (in Figure 21).

It can be seen that by increasing the peel stopper angle the crack kinking at the tri-material junction becomes more difficult, especially for $\mathrm{C} 2$ and C3. For the case tested in this study, at $10^{\circ}$ the fracture toughness ratio needed to obtain crack deflection is similar for $\mathrm{C} 2$ and $\mathrm{C} 3$, while for $\mathrm{C} 1$ the ratio is significantly higher. These observations agree well with results presented in [7] which considered the efficiency of peel stoppers to deflect and arrest propagating face-sheet/core interface cracks under mode II dominated stress fields in the vicinity of the tri-material junction.

Figure 21 explains the behavior observed for $\mathrm{C} 1$ (straight crack path followed in 2 of 3 cases). Since the required fracture toughness ratio must be below the energy release rate ratio, the straight path interface fracture toughness $\left(\Gamma(\psi)_{\text {straight }}\right)$ must be larger than the interface fracture toughness at the deflected path. It may be assumed that the material systems at the two interfaces have comparatively similar interface fracture properties since the bonding is achieved by the infused epoxy resin and an epoxy glue respectively. The possibility of the fracture toughness ratio and the energy release ratio being both close to 1 explains why in one of the tests crack deflection was observed around the tri-material junction. Crack deflection may occur occasionally in $\mathrm{C} 1$ if the two ratios are close to being equal.

$\mathrm{C} 2$ and $\mathrm{C} 3$ represent an effort to increase the straight path interface fracture toughness by using glass fibers reinforced with resin and thus lowering the fracture toughness ratio. For a crack to propagate straight ahead it has first to break the fibres at the straight path interface. In both configurations the increase is local, only around the crack tip, where the fibres are "sticking out" or laid in front of the peel stopper. Even though in Figure 21, the energy release rate ratio at $10^{\circ}$ is $\frac{G_{\text {deflected }}}{G_{\text {straight }}}=0.75$, the mode I fracture toughness of the fibers is several times higher than that of epoxy [24] thus explaining why C2 and C3 generally were shown to enable crack deflection as required.

\section{Conclusions}

The geometry and material composition of a previously proposed (original) peel stopper $[5,6$, 7] was modified to a ' $U$ ' shape to reduce the volume and mass, and glass fibre layers were introduced into the peel stopper material (PU) to increase the fracture toughness. Using the new peel stopper concept, three different configurations of the peel stopper $(\mathrm{C} 1, \mathrm{C} 2$ and $\mathrm{C} 3)$ were proposed. $\mathrm{C} 1$ has the same configuration at the tri-material junction as that of the original peel stopper (the peel stopper is directly bonded to the foam core). For C2 reinforcement fibres inside the peel stopper protrudes from the peel stopper tip and are attached to the face sheet by bonding through the infusion process. For $\mathrm{C} 3$ an inter-fibre layer glass fabric is placed along the peel stopper/core interface and the part of the fibre-layer extending from the peel stopper tip is bonded to the face sheet in the infusion process. The mechanisms controlling the crack propagation at the tri-material junction were studied using both TSA and FE analysis. The main findings can be summarised as: 
Wang. W, Martakos, G., Dulieu-Barton, J.M., Andreasen, J.H. and Thomsen, O.T., "Fracture Behaviour at trimaterial junctions of crack stoppers in sandwich structures" Composite Structures, 133, 2015, 818-833.

http://dx.doi.org/10.1016/j.compstruct.2015.07.060

1. The local effects induced near the peel stopper tip for the different peel stopper configurations were quantified using TSA. It was shown that the local effects induced near the peel stopper tip were significantly influenced by the type of peel stopper used.

2. When the interfacial crack reached the tri-material junction for the $\mathrm{C} 1$ specimens, large stresses were identified ahead of the peel stopper tip in the face sheet. However, an increase in the stresses at the peel stopper/core interface was observed for configurations $\mathrm{C} 2$ and $\mathrm{C} 3$. It has been demonstrated that the large stresses ahead of the peel stopper tip for $\mathrm{C} 1$ indicate the presence of significant interfacial peeling stresses which result in crack propagation along the face sheet/peel stopper interface. For $\mathrm{C} 2$ and $\mathrm{C} 3$ it was demonstrated that interfacial peeling stresses are primarily induced along the peel stopper/core interface, thus promoting crack deflection.

3. For specimens $\mathrm{C} 1$ and $\mathrm{C} 3$ an increase in face sheet stresses was induced ahead of the peel stopper tip when the crack had passed the tri-material junction. This indicates a weak bonding at the face sheet/peel stopper where debonding initiated.

4. The capability of achieving crack deflection of the 3 peel stopper configurations as a function of the peel stopper angle was investigated using FE analysis. The energy release rate and the mode-mixity associated with different peel stopper angles and crack paths were studied. It has been shown that by increasing the peel stopper angle, crack deflection at the tri-material junction becomes increasingly more difficult. In the study the $10^{\circ}$ angle was the one tested since it represents the more practical solution.

5. For the tested $10^{\circ}$ angle, the energy release rate for the two possible crack paths, crack propagating straight and crack deflecting at the peel stopper were used to derive results on the crack deflection ability of each configuration. It was shown that if the ratio of the energy release rates for the two crack paths is equal (or near equal) to the ratio of the interface fracture toughnesses of the two crack paths, then crack deflection at the peel stopper is unlikely to occur as observed for $\mathrm{C} 1$. To ensure crack deflection it was found that the interface fracture toughness of the straight path must be large compared to the interface fracture toughness of the deflected crack path. By placing/embedding fibres in front of the peel stopper tip in $\mathrm{C} 2$ and $\mathrm{C} 3$ the desired behavior was achieved and the crack is deflected every time, as was confirmed in the experiments.

\section{Acknowledgements}

The work presented was co-sponsored by the University of Southampton and the Danish Council for Independent Research | Technology and Production Sciences (FTP), under the research project 'Enhanced Performance of Sandwich Structures by Improved Damage Tolerance' ('SANTOL'). The financial support received is gratefully acknowledged. The foam material supported by DIAB AB Sweden is highly appreciated.

\section{References}

1. D. Zenkert, An introduction to sandwich construction. EMAS, London (1997).

2. Y. Hirose, G. Matsubara, M. Hojo, H. Matsuda, F. Inamura, Evaluation of modified crack arrester by fracture toughness tests under mode I type and mode II type loading for foam core sandwich panel, In: Proc. US-Japan conference on composite materials 2008, Tokyo, Japan, 2008. 
Wang. W, Martakos, G., Dulieu-Barton, J.M., Andreasen, J.H. and Thomsen, O.T., "Fracture Behaviour at trimaterial junctions of crack stoppers in sandwich structures" Composite Structures, 133, 2015, 818-833.

http://dx.doi.org/10.1016/j.compstruct.2015.07.060

3. Y. Hirose, H. Matsuda, G. Matsubara, F. Inamura, Evaluation of new crack suppression method for foam core sandwich panel via fracture toughness tests and analyses under mode-I type loading, Journal of Sandwich Structures \& Materials 11 (6) (2009) 451-470.

4. M. Rinker, P. C. Zahlen, M. John, R Schäuble, Investigation of sandwich crack stop elements under fatigue loading, Journal of Sandwich Structures \& Materials, 14 (1) (2012) $55-73$.

5. J. Jakobsen, E. Bozhevolnaya, O.T. Thomsen, New peel stopper concept for sandwich structures. Composites Science and Technology 67 (2007) 3378-3385.

6. E. Bozhevolnaya, J. Jakobsen, O.T. Thomsen, Fatigue performance of sandwich beams with peel stoppers, strain 45 (4) (2009) 349-357.

7. J. Jakobsen, J.H. Andreasen, O.T. Thomsen, Crack deflection by core junctions in sandwich structures, Engineering fracture mechanics (14) (2009) 2135-2147.

8. J. Jakobsen, O.T. Thomsen, J.H. Andreasen, E. Bozhevolnaya, Crack deflection analyses of different peel stopper design for sandwich structure, Composite Science and Technology 69 (6) (2009)870-875.

9. J.M. Dulieu-Barton, P. Stanley, Development and applications of thermoelastic stress analysis, Journal of strain analysis 33 (2) (1998) 93-104.

10. W. Wang, R.K. Fruehmann, J.M. Dulieu-Barton, A high spatial resolution motion compensation method for thermoelastic stress analysis, submitted.

11. B. Pan, K. Qian, H. Xie, A. Asundi, Two-dimensional digital image correlation for inplane displacement and strain measurement: a review, Measurement science and technology 20 (6) (2009).

12. Z. Suo, Singularities, interfaces and cracks in dissimilar media. Proceedings of the Royal Society of London, Series A, Measurement and Physical Sciences 427 (1990), 331-358.

13. C. Berggreen, Damage tolerance of debonded sandwich structures. Technical University of Denmark, PhD thesis, Department of Mechanical Engineering, Maritime Engineering, 2004.

14. C. Berggreen, L. A. Carlsson, A modified TSD specimen for fracture toughness characterization - fracture mechanics analysis and design. Journal of Composite Materials 44 (15) (2010) 1893-1912.

15. S. Zhang, J.M. Dulieu-Barton, R.K. Fruehmann, O.T. Thomsen, A Methodology for Obtaining Material Properties of Polymeric Foam at Elevated Temperatures, Experimental Mechanics 52 (2012) 3-15.

16. A. Quispitupa, C. Berggreen, L.A. Carlsson, On the analysis of a mixed mode bending sandwich specimen for debond fracture characterization, Engineering Fracture Mechanics76 (2009) 594-613.

17. J.W. Hutchinson, Z. Suo, Mixed Mode Cracking in Layered Materials, Advances in Applied Mechanics 29 (1992) 63-191.

18. M. He, J.W. Hutchinson, Kinking of a crack out of an interface, Journal of Applied Mechanics, 111 (1989) 270-278.

19. T.C. Wang, Kinking of an interface crack between two dissimilar anisotropic elastic solids, International Journal of Solids and Structures 31 (5) (1994) 629-641.

20. http://148.204.81.206/Ansys/readme.html.

21. W. Wang, J.M. Dulieu-Barton, O.T. Thomsen, A methodology for characterizing the interfacial fracture toughness of sandwich structures using high speed infrared thermography, submitted. 
Wang. W, Martakos, G., Dulieu-Barton, J.M., Andreasen, J.H. and Thomsen, O.T., "Fracture Behaviour at trimaterial junctions of crack stoppers in sandwich structures" Composite Structures, 133, 2015, 818-833.

http://dx.doi.org/10.1016/j.compstruct.2015.07.060

22. M. Manca, A. Quispitupa, C, Berggreen, L.A. Carlsson, Face/core debond fatigue crack growth characterization using the sandwich mixed mode bending specimen, Composites Part A: Applied Science and Manufacturing, 43 (11) (2012) 2120-2127.

23. W. Wang, Infrared techniques for quantitative evaluation of interfacial fracture behavior and damage tolerance in sandwich structures, PhD thesis, University of Southampton, 2015.

24. M. F. Ashby, Materials Selection in Mechanical Design. Butterworth-Heinemann (2011). 

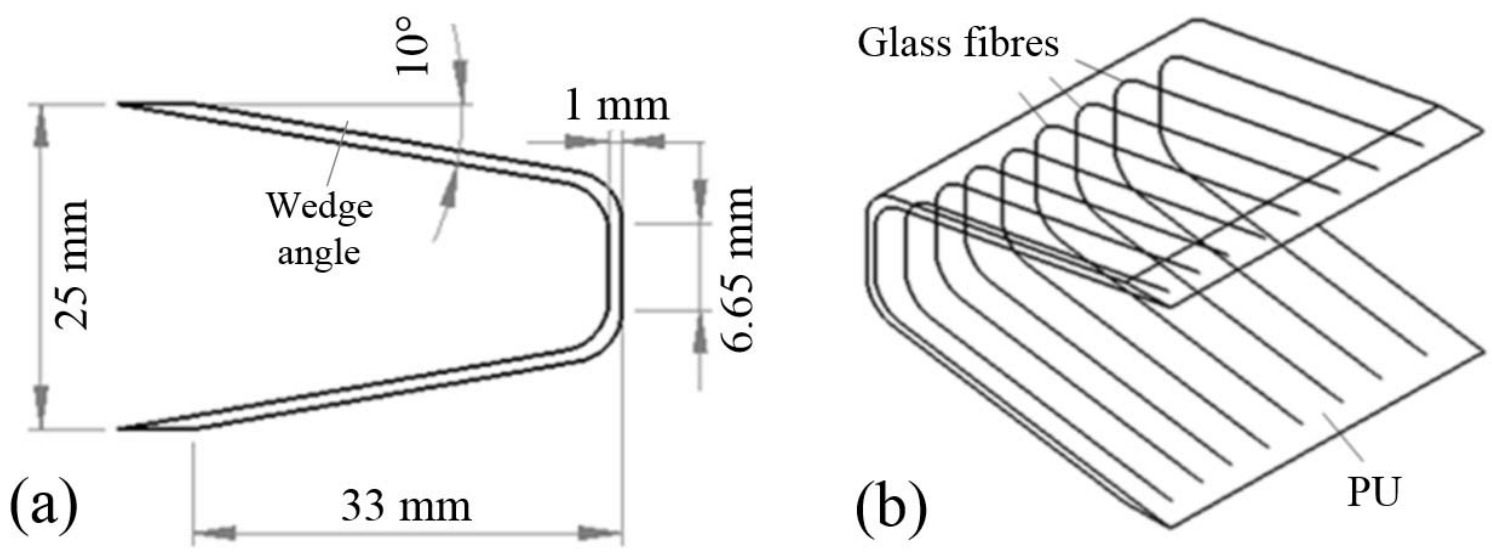

Figure 1: (a) Peel stopper shape and fibre reinforcement alignment inside the PU material and (b) the dimension of the peel stopper.
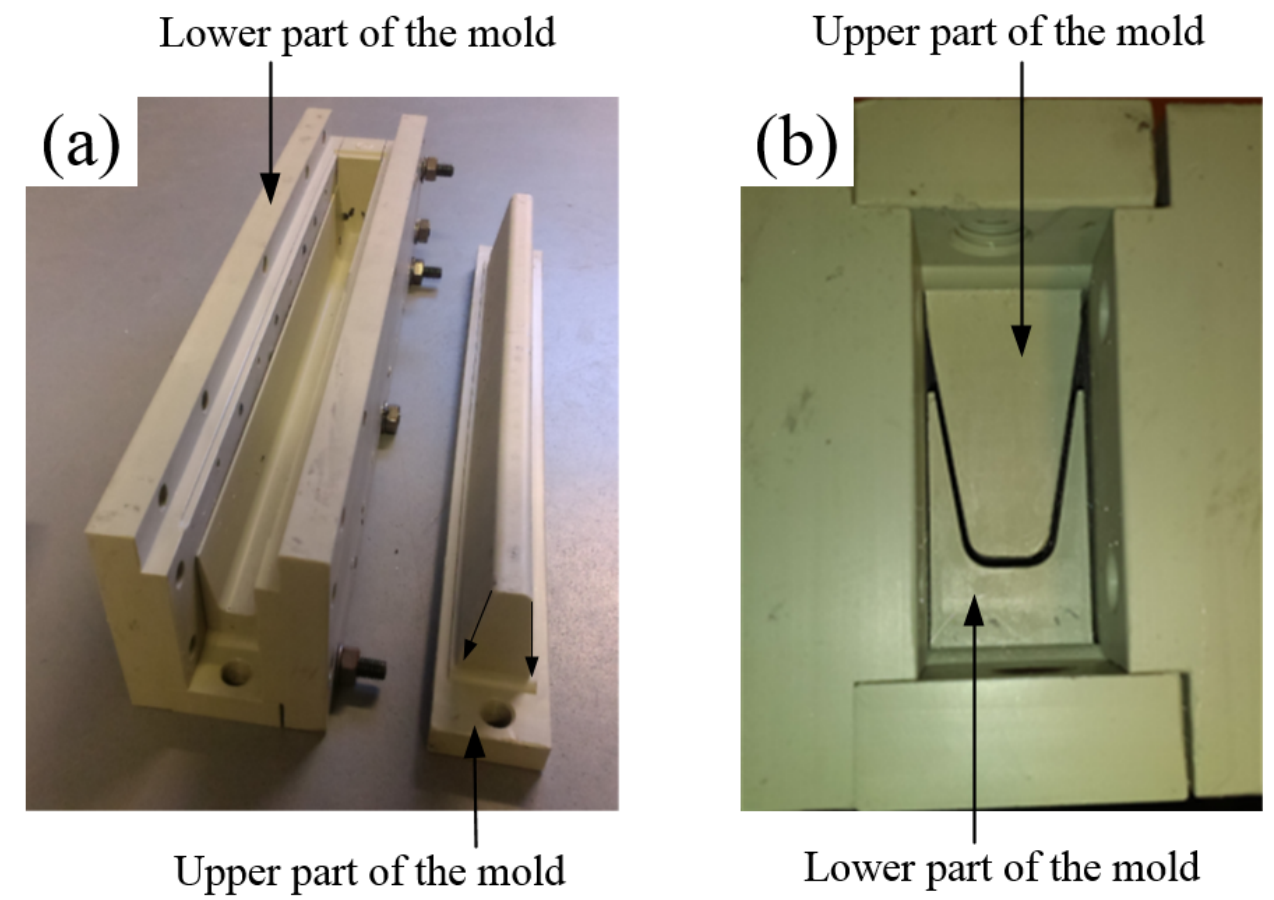

Figure 2: (a) The lower and upper parts of the peel stopper polypropylene mould and (b) side view of the assembled mould showing the peel stopper shape 

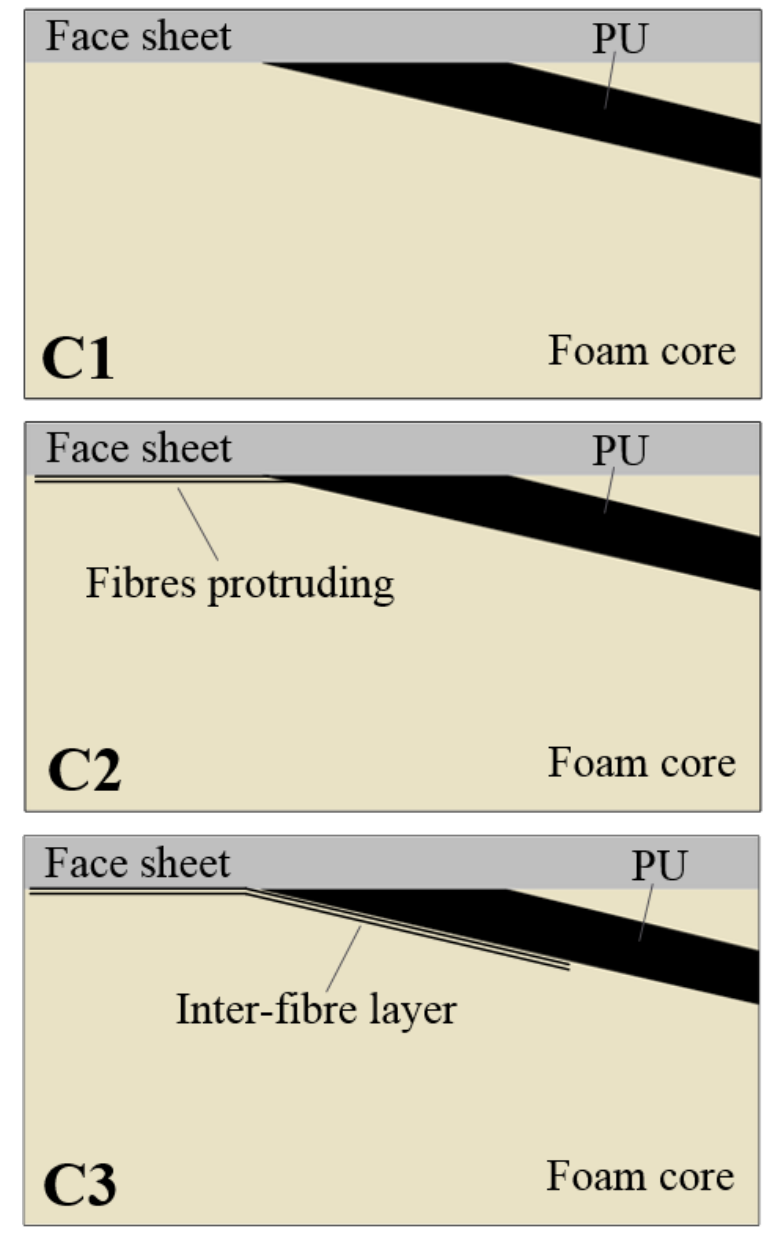

Figure 3: The three peel stopper configurations

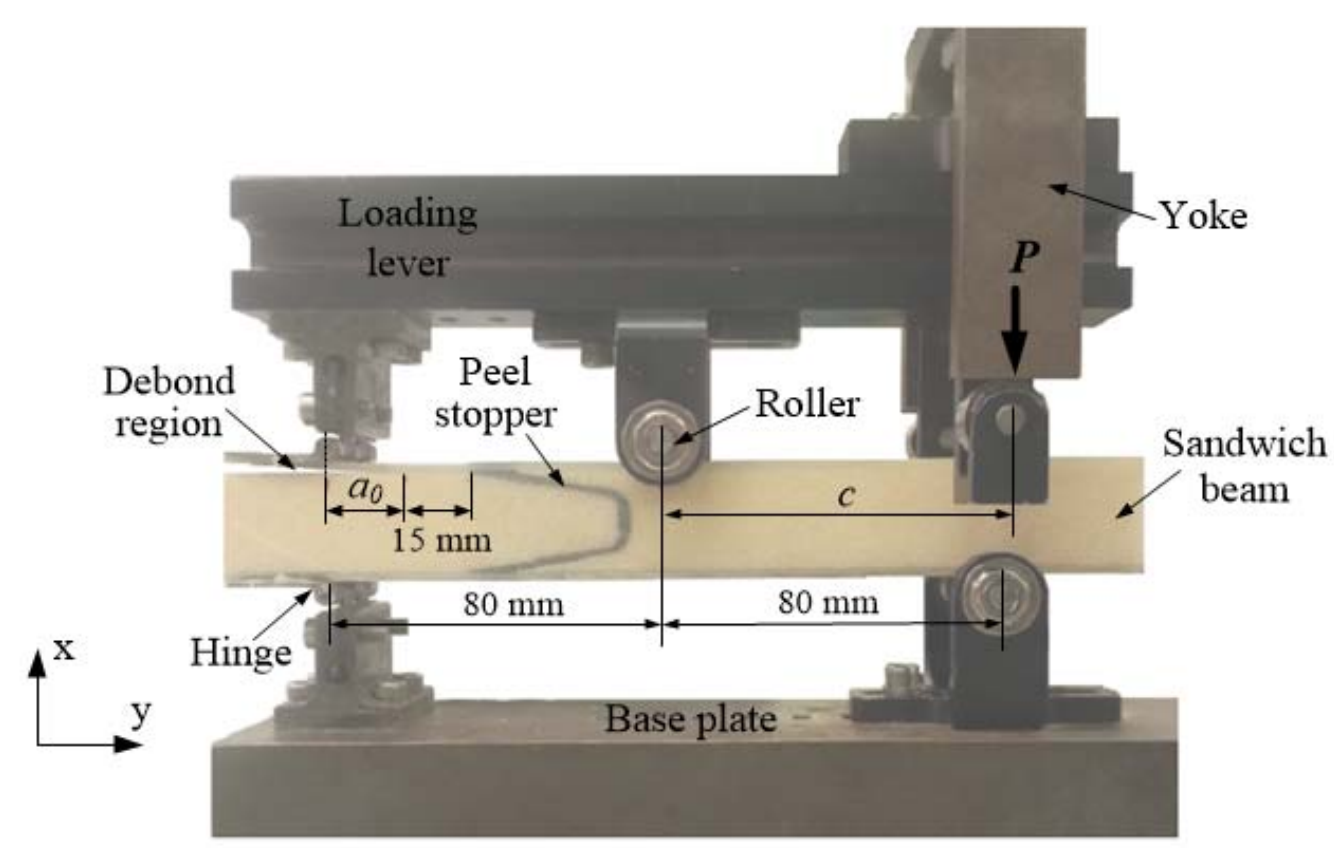

Figure 4: Sandwich beam specimen with peel stopper loaded in the MMB test rig 

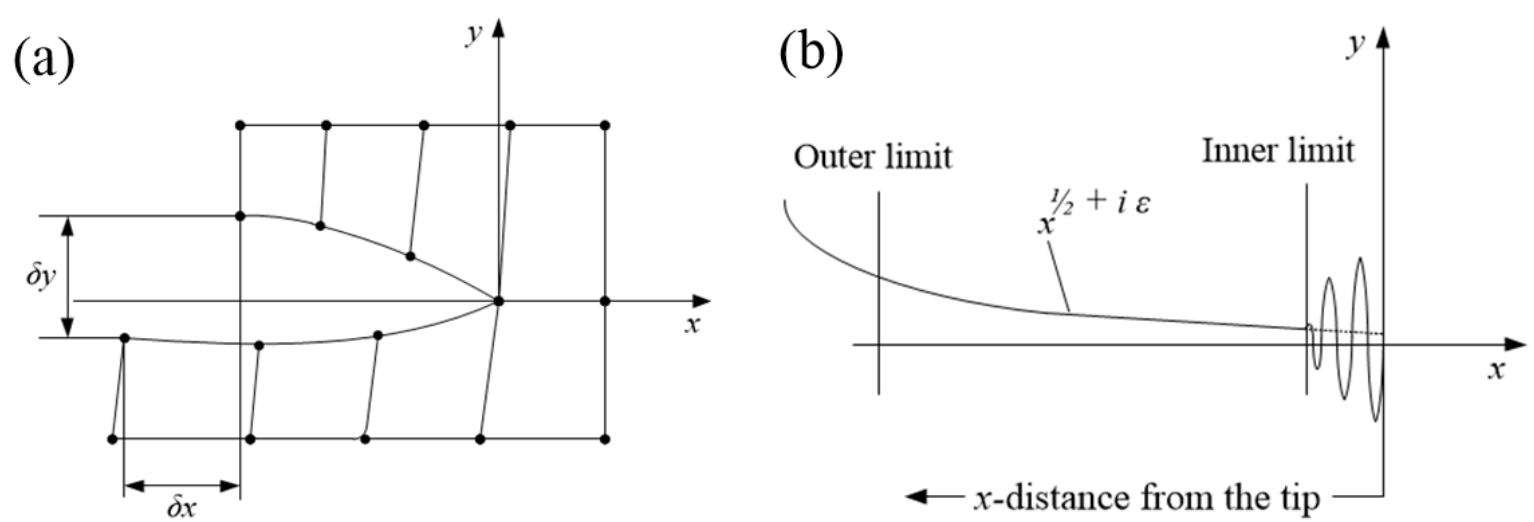

Figure 5. (a) Extraction of displacement data from the local coordinate system in the FE model, and (b) Schematic representation of CSDE method

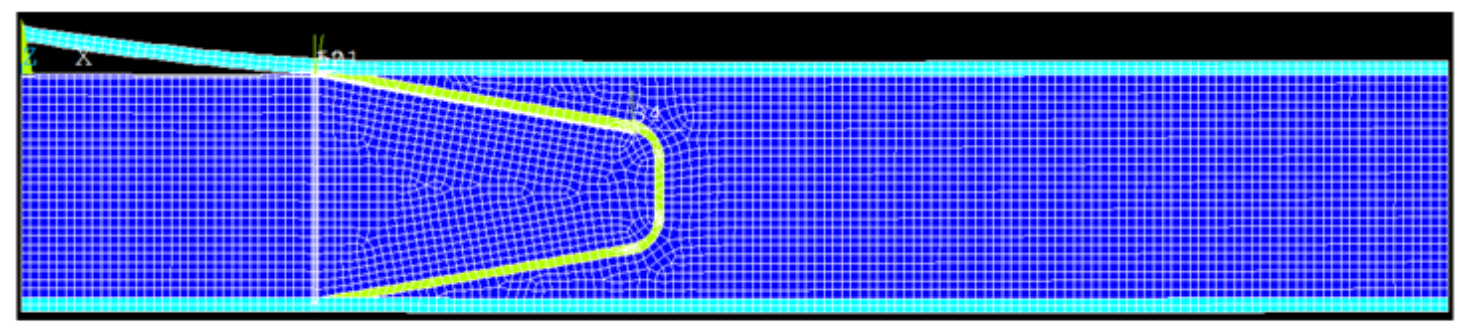

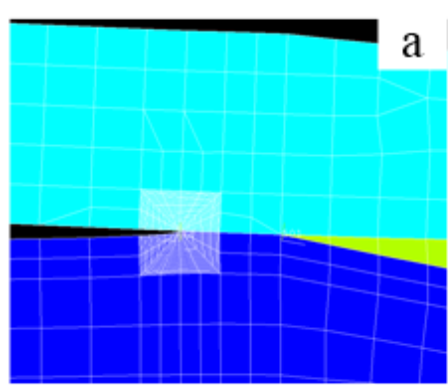

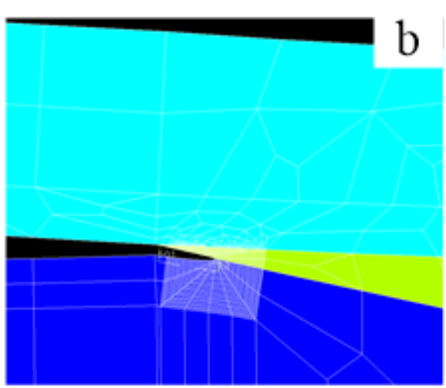

$\mathrm{C} 1$
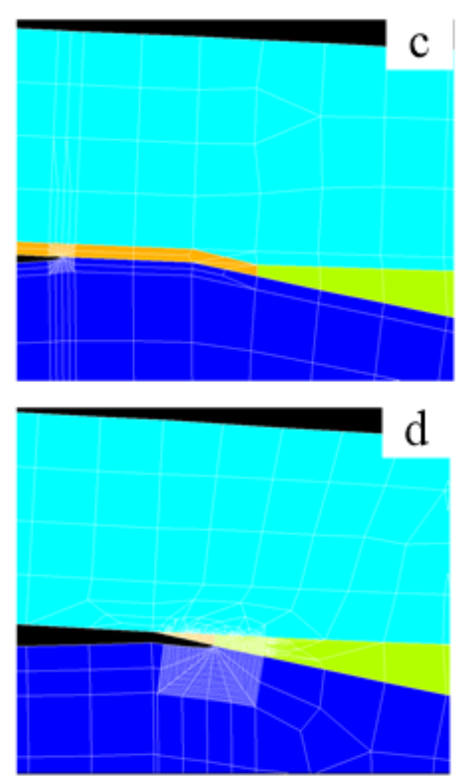

$\mathrm{C} 2$

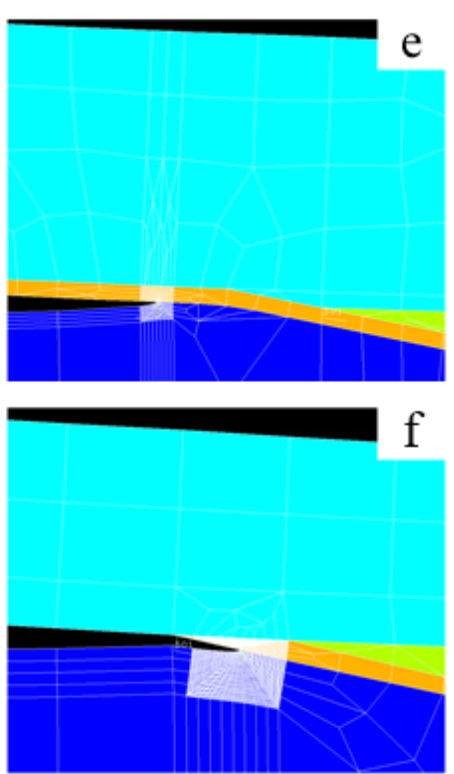

$\mathrm{C} 3$

Figure 6: FE models of the sandwich specimens corresponding to different crack path scenarios near the tri-material junction for $\mathrm{C} 1$ ( $\mathrm{a}$ and b), $\mathrm{C} 2$ (c and d) and $\mathrm{C} 3$ (e and f). 


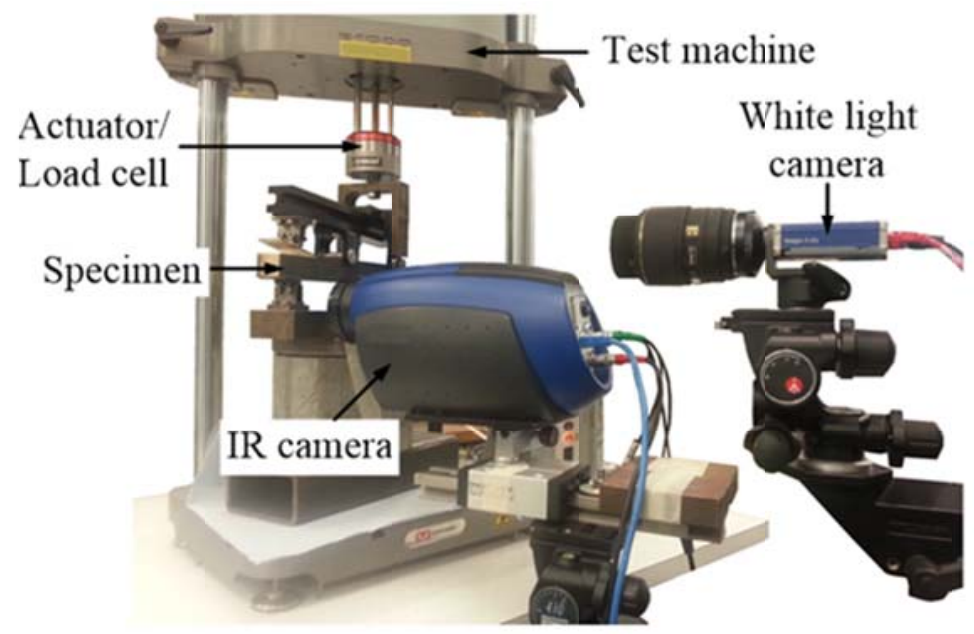

Figure 7: Test setup for the TSA measurement in the fatigue test

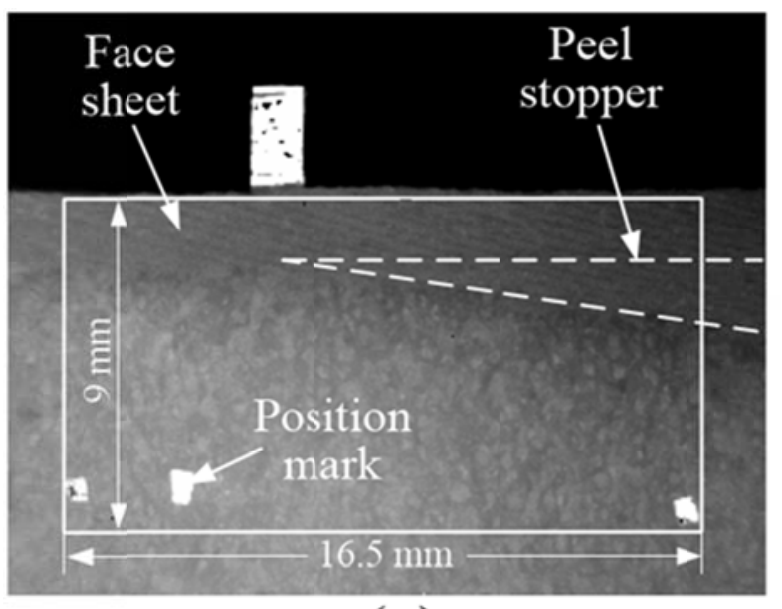

(a)

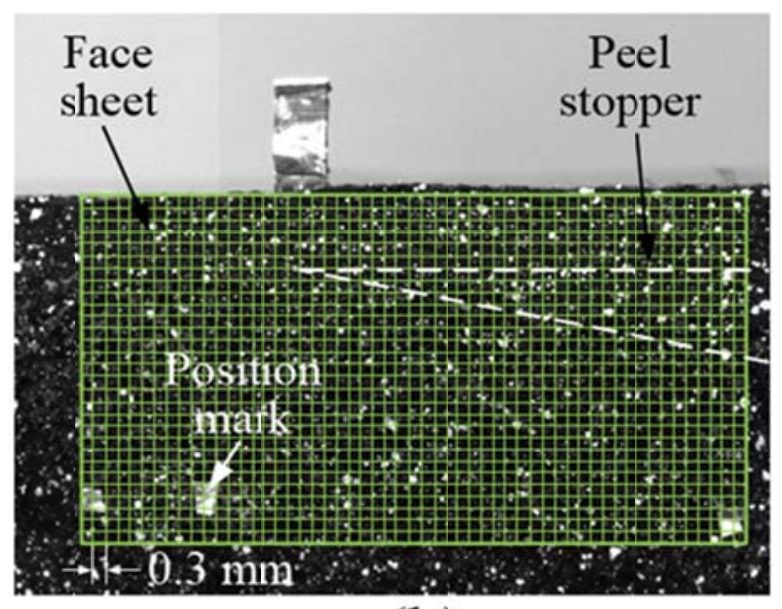

(b)

Figure 8: (a) Thermal image and (b) white light image collected from the specimen surface in the neighbourhood of the tri-material junction 

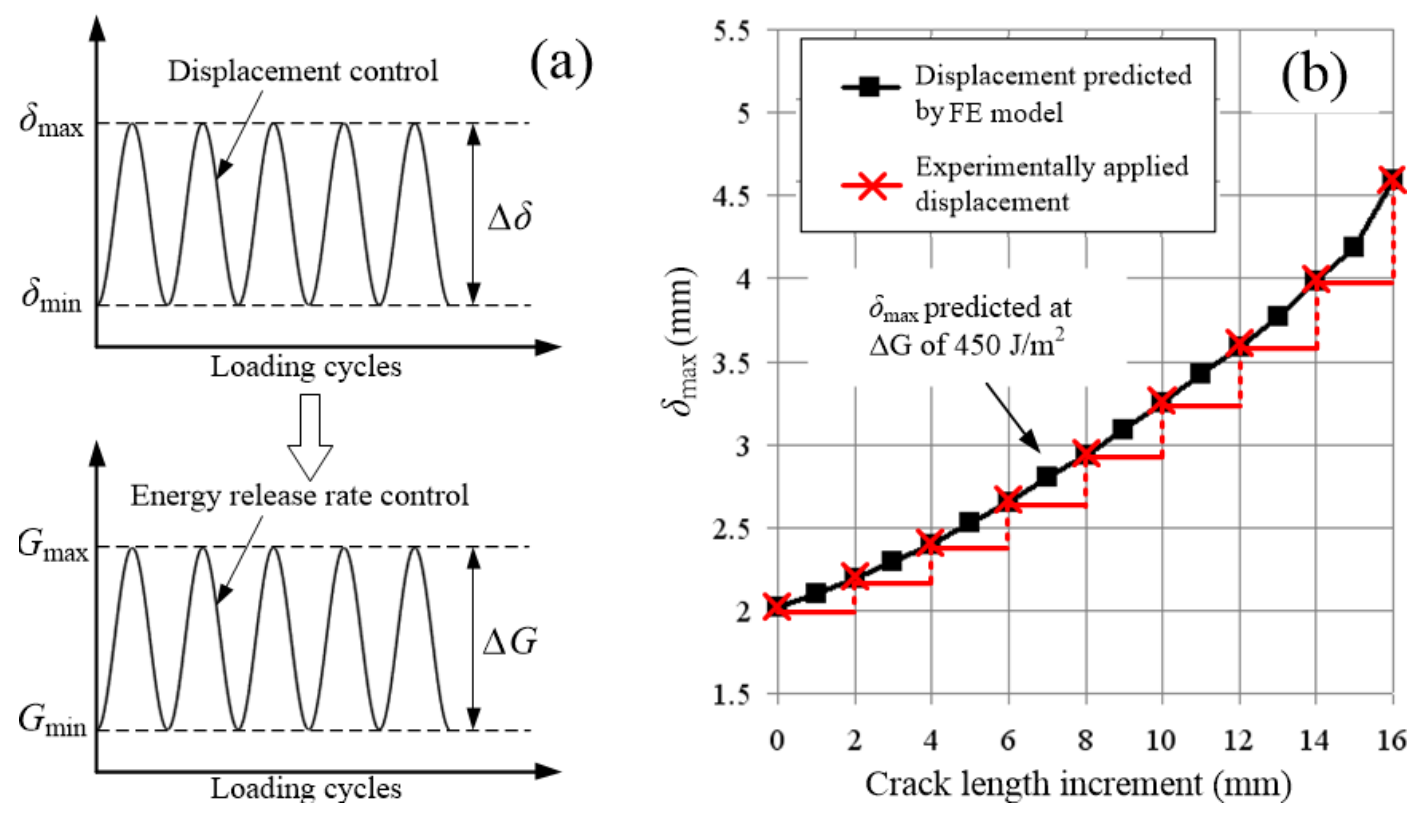

Figure 9: (a) Displacement control and energy release rate control in the fatigue test, (b) $\delta_{\max }$ against crack increment at $\Delta G$ of $450 \mathrm{~J} / \mathrm{m}^{2}$

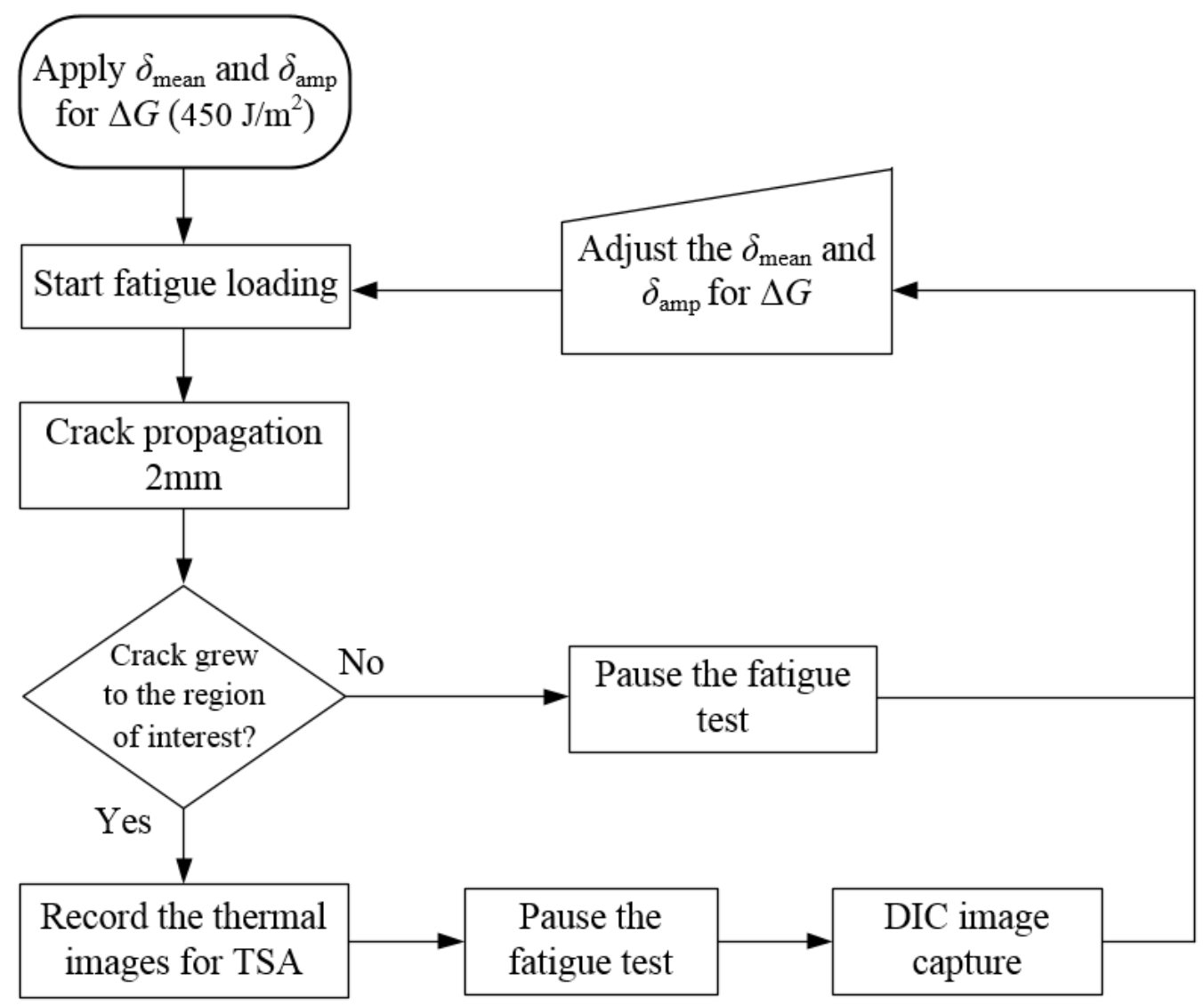

Figure 10: Flowchart of the fatigue test procedure 

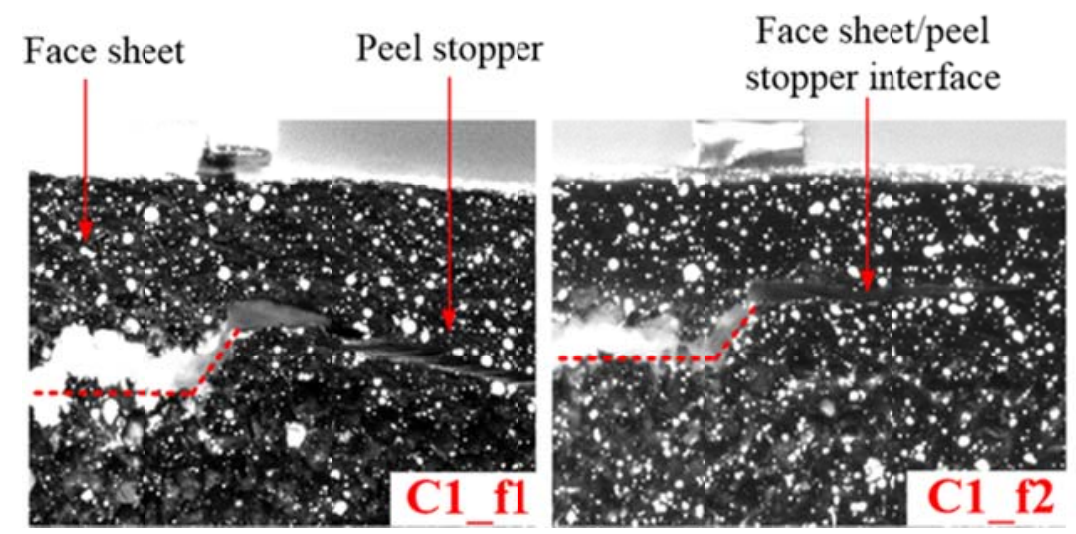

Face sheet/peel stopper interface

Figure 11: Crack paths at the tri-material junction observed from specimens $\mathrm{Cl}$
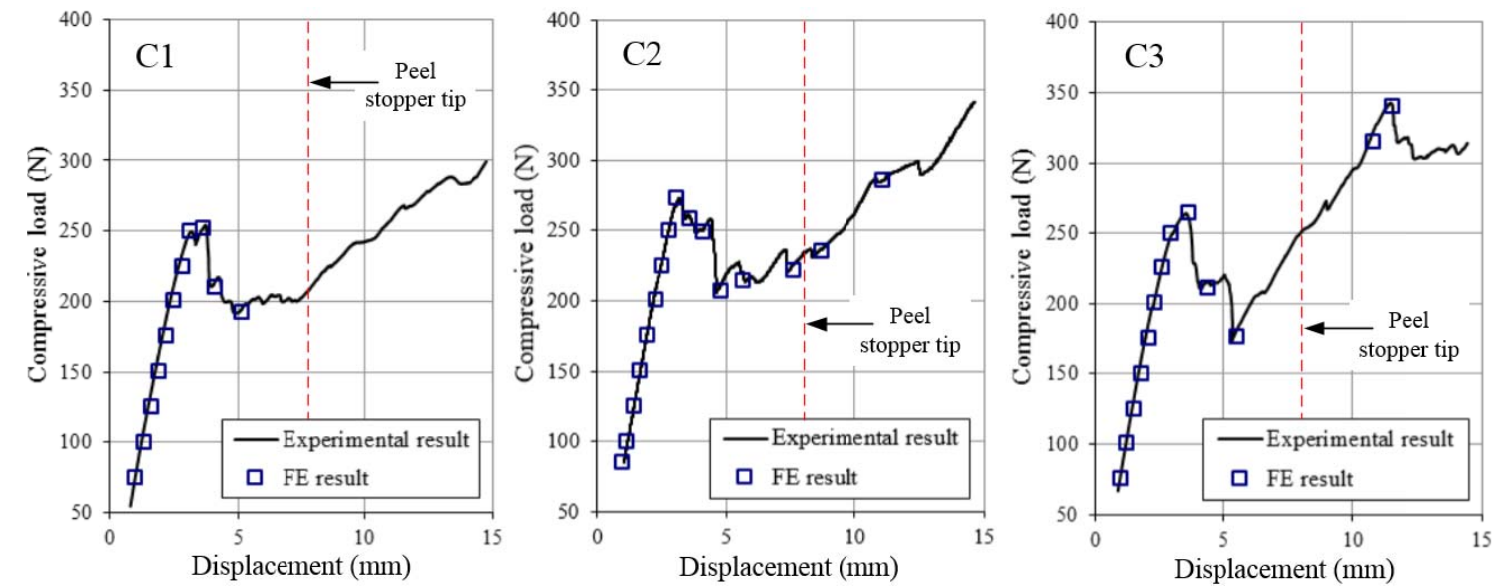

Figure 12: Comparison of the results between the experiments and the FEA for different peel stopper configurations

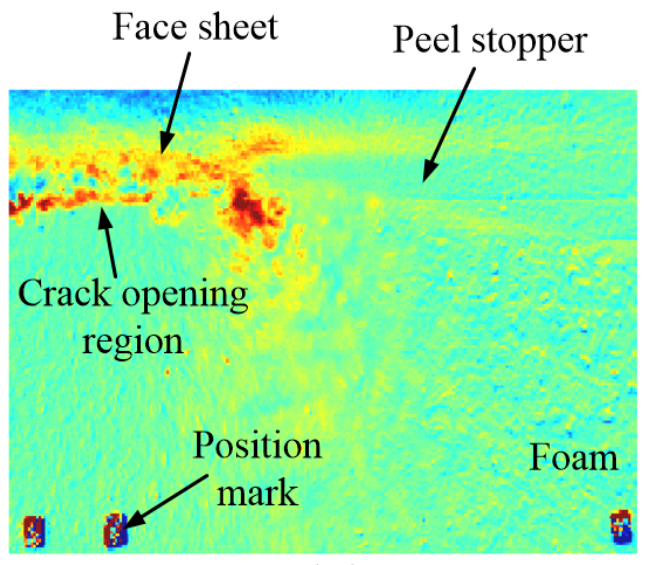

(a)

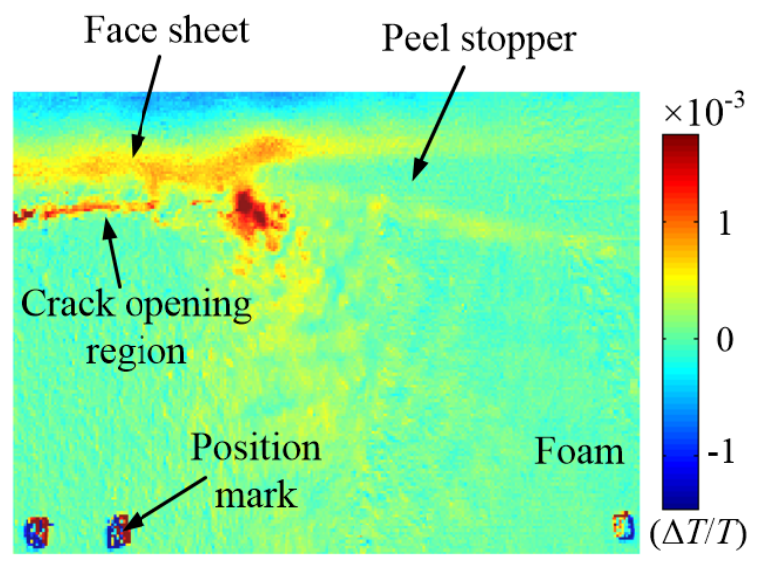

(b)

Figure 13: Comparison of the TSA results before (a) and after (b) motion compensation 


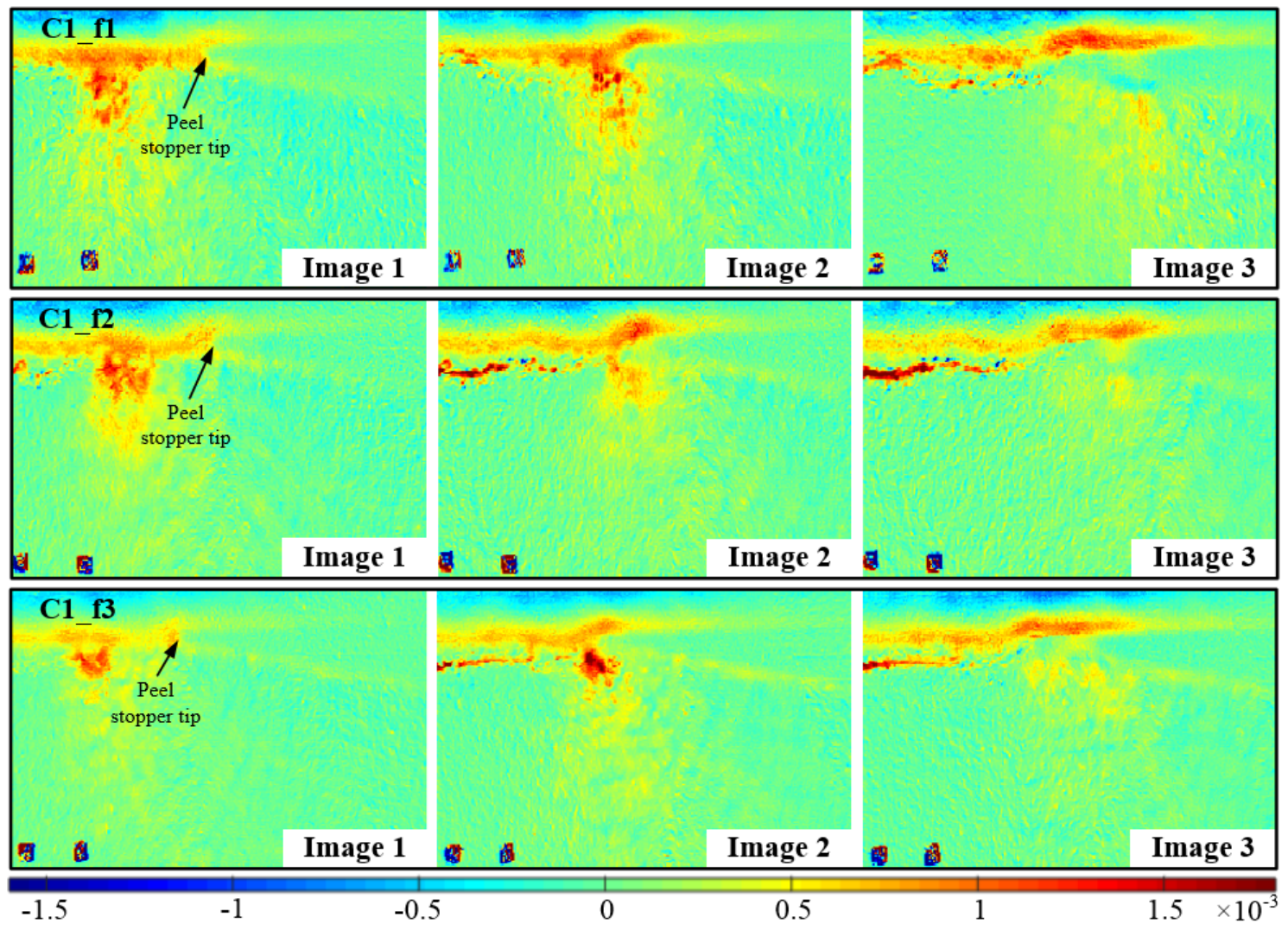

Figure 14: $\Delta T / T$ obtained from the neighbourhood of the tri-material junction from specimens C1

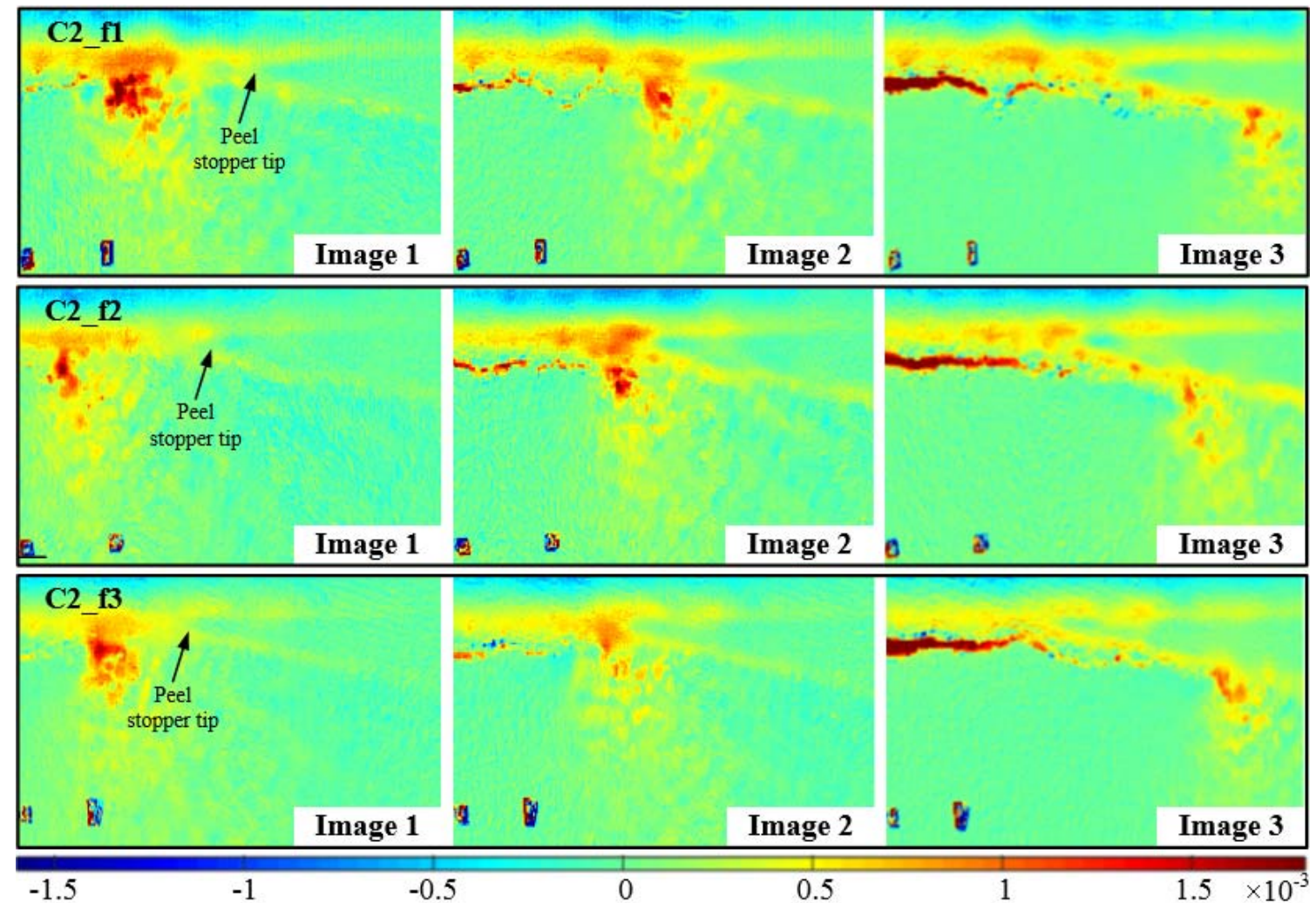

Figure 15: $\Delta T / T$ obtained from the neighbourhood of the tri-material junction from specimens C2 


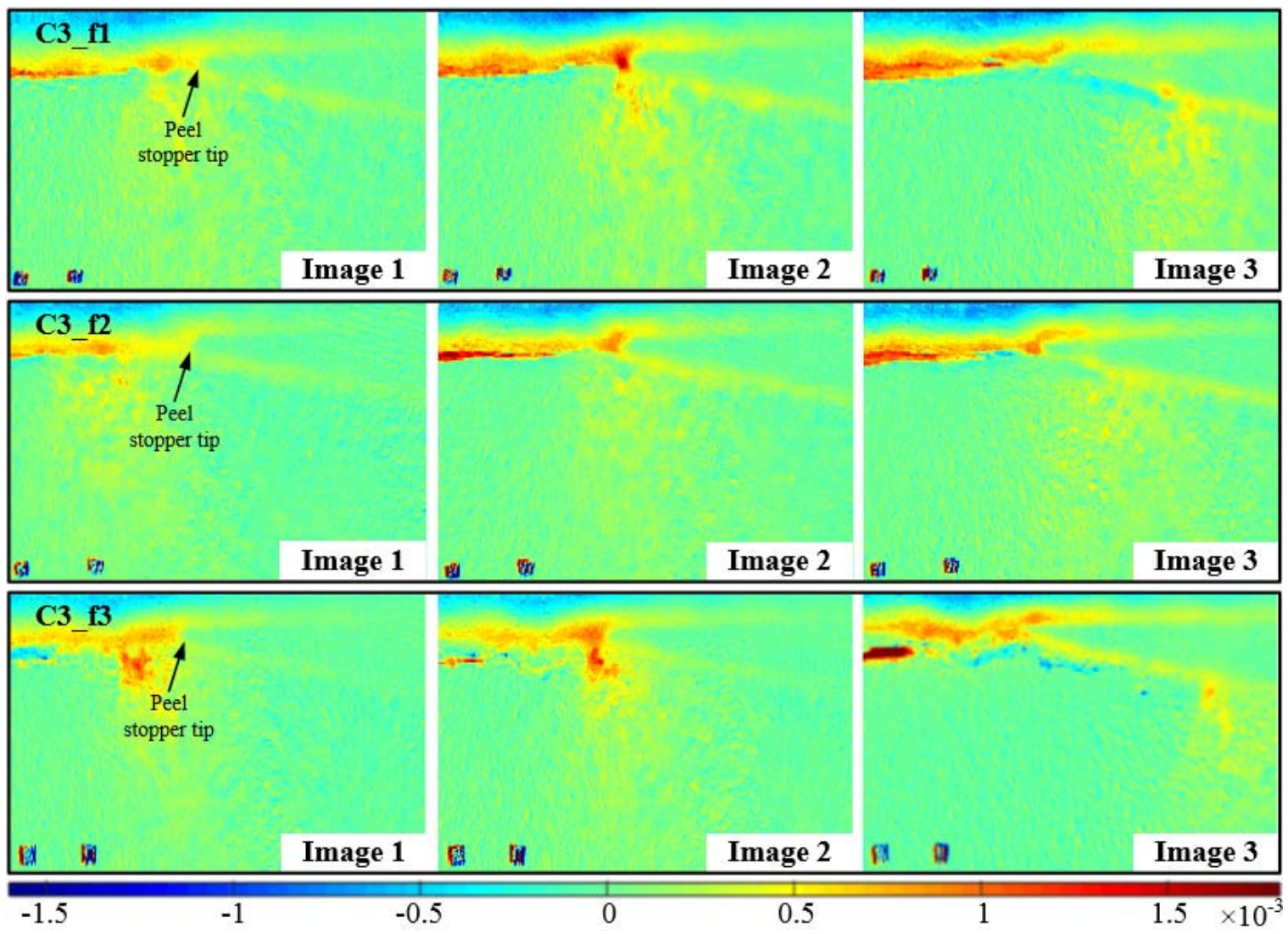

Figure 16: $\Delta T / T$ obtained from the neighbourhood of the tri-material junction from specimens $\mathrm{C} 3$

(a)

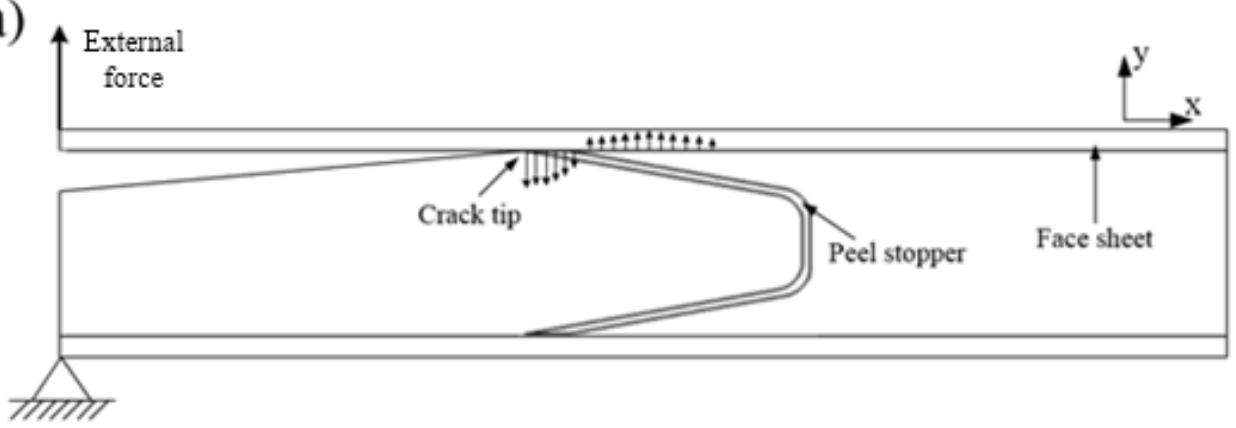

(b)

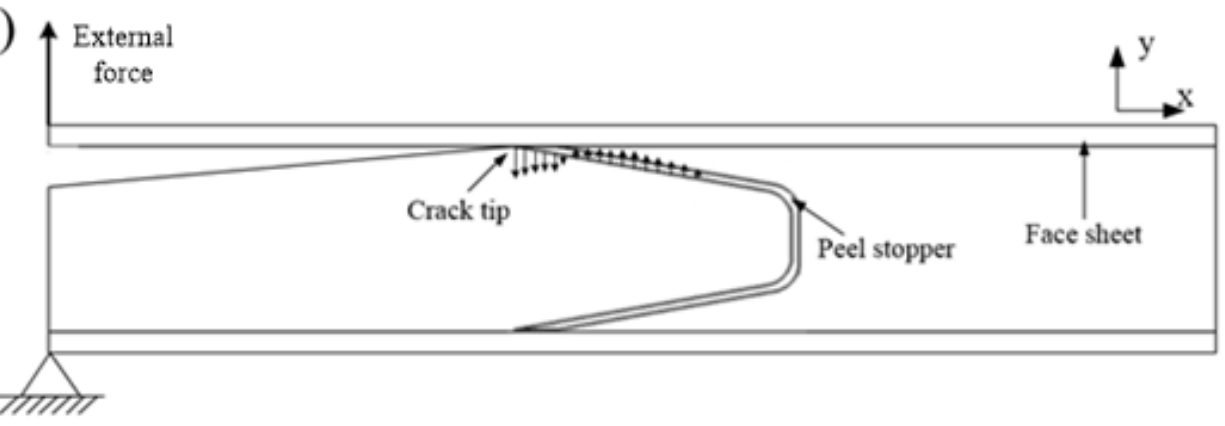

Figure 17: Force diagram of the debonded sandwich beam specimen associated with (a) crack path at the face sheet/peel stopper interface and (b) crack path at the peel stopper/core interface 


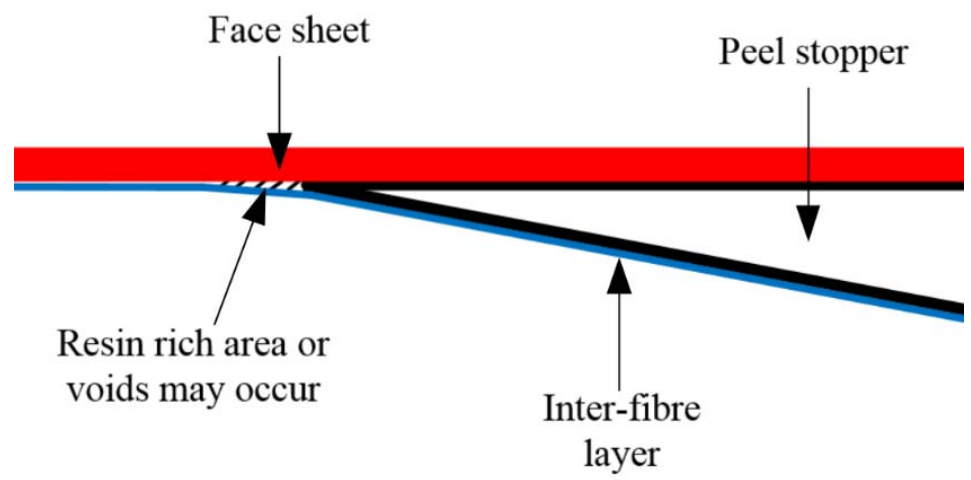

Figure 18: Sketch of the tri-material junction for specimens C3

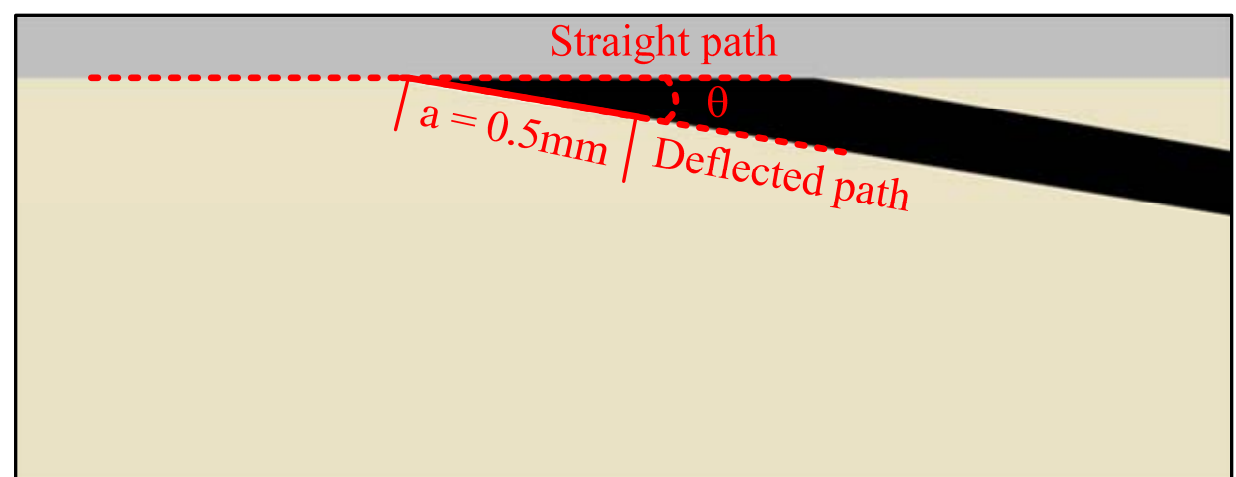

Figure 19: Crack paths investigated around the tri-material junction. 


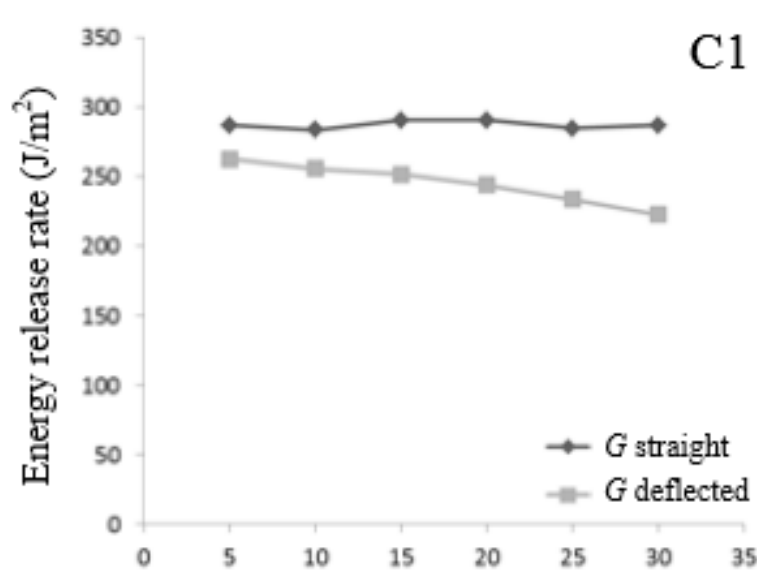

$\theta$, peel stopper angle
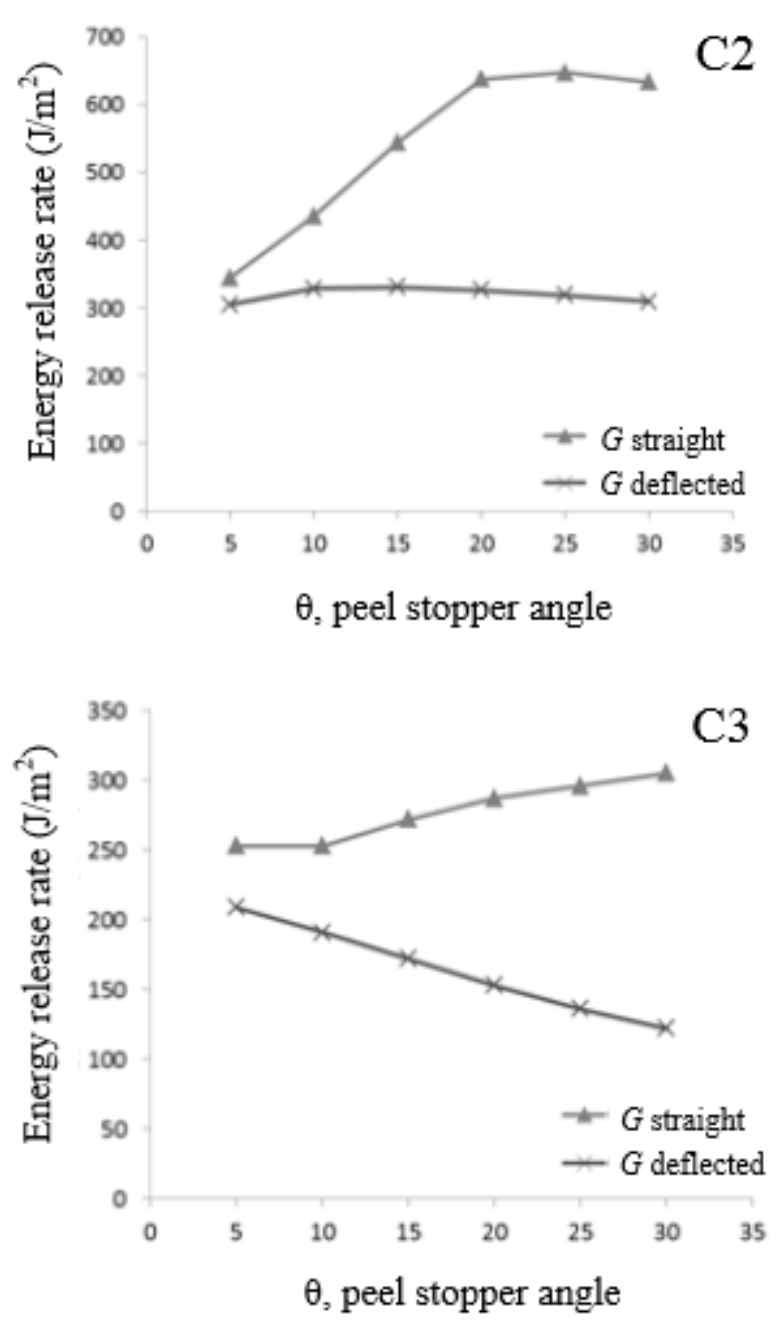

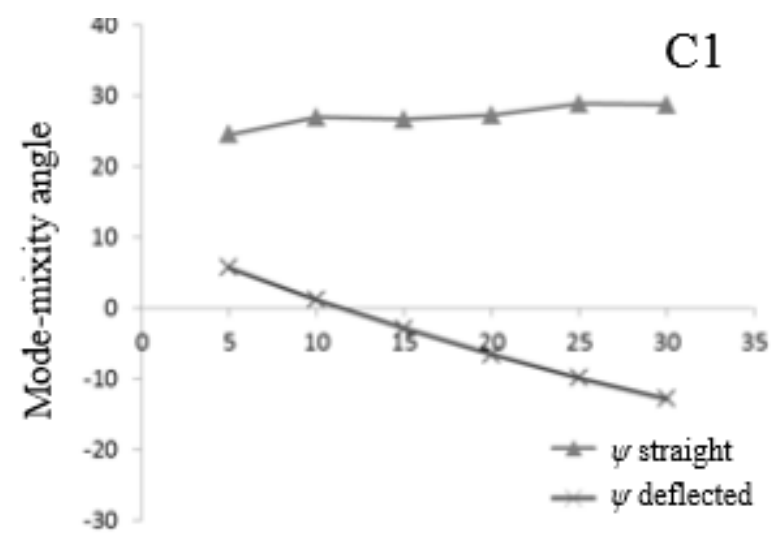

$\theta$, peel stopper angle

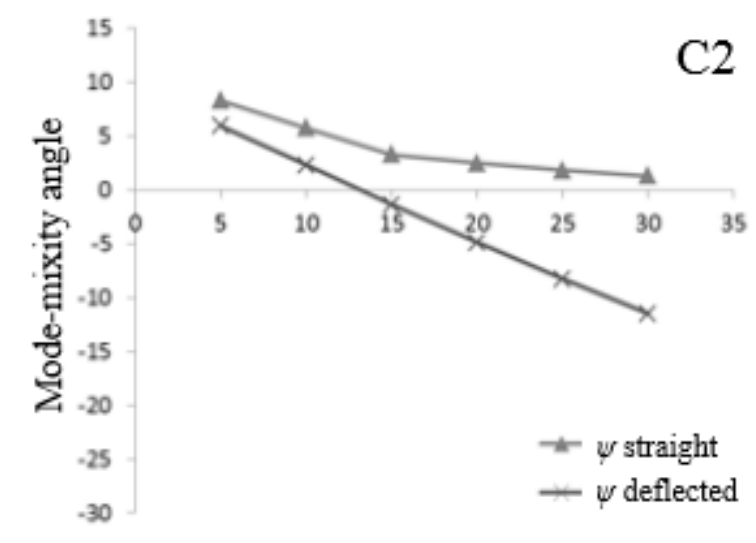

$\theta$, peel stopper angle

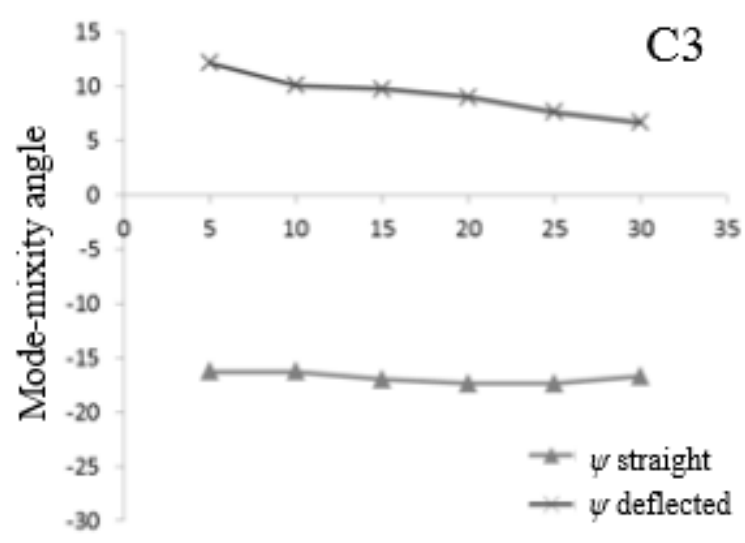

$\theta$, peel stopper angle

Figure 20: Left: Predicted energy release rate vs. peel stopper angle for the three peel stopper configurations. Right: Predicted mode-mixity vs. peel stopper angle for the three peel stopper configurations. 


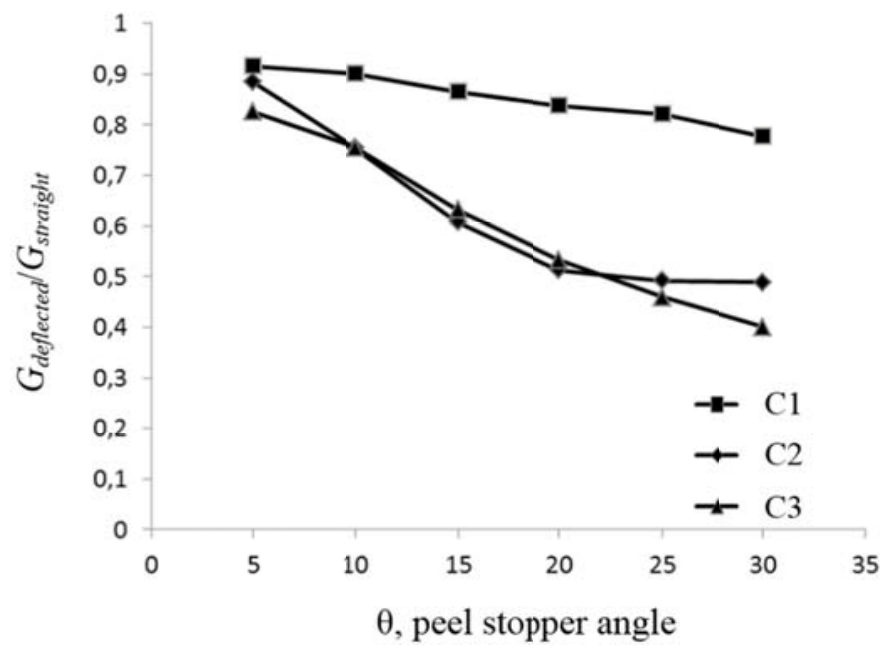

Figure 21: $\frac{G_{\text {deflected }}}{G_{\text {straight }}}$ vs. peel stopper angle $\theta$. 